\title{
Emergencia de comunidades pastoralistas formativas en el sureste de la Puna de Atacama ${ }^{1}$
} lautaro Núñez A. $^{2}$, Isabel Cartajena F. ${ }^{3}$, Carlos Carrasco G. $^{4}{ }^{6}$,
Patricio de Souza H..$^{5}$ y Martin Grosjean

\section{RESUMEN}

Se sintetizan los resultados de una investigación multidisciplinaria orientada a comprender la transición entre sociedades arcaicas tardías (ca. 5000-3800 AP) y formativas tempranas (ca. 3500-2400 AP). Se propone que la ubicación de los asentamientos arcaicos y formativos en el ecorrefugio de quebrada de Tulan, se explica por un conjunto de condiciones culturales, sociales y ambientales favorables, las cuales permitieron el cambio desde una sociedad cazadora-recolectora a otra principalmente pastoralista. La evidencia arquitectónica de carácter ceremonial junto a la aparición de nuevas tecnologías, como la cerámica, litoescultura, metalurgia en oro, entre otras, y la profusión de arte rupestre, nos indican un temprano proceso de complejización en la vertiente occidental de las tierras circumpuneñas.

Palabras claves: quebrada Tulan - transición Arcaico-Formativo - Formativo Temprano - pastoralismo arquitecura ceremonial.

\begin{abstract}
A summary of results of multidisciplinary research aimed to the understanding of the transition between late archaic (ca. 5000-3800 BP) to early formative societies (ca. 3500-2400 $B P)$, is presented. We suggest that the location of archaic and formative settlements in the ecorefuge of Quebrada Tulan are explained by a favorable cultural, social and environmental conditions, that allowed the transformation from a hunter gatherer society to a pastoralist one. The evidence of ceremonial architecture, the appearance of new technologies such us pottery, lito-sculpture, gold metallurgy between others and the profusion of rock art, may indicate an early complexity process in the western slope of the Circumpuna.
\end{abstract}

1 Proyecto FONDECYT 1020316: "Transición del Arcaico Tardío al Formativo Temprano en la cuenca de Atacama: Emergencia de complejidad sociocultural en el Subárea Circumpuneña".

2 Instituto de Investigaciones Arqueológicas y Museo R. P. Gustavo Le Paige s. j., Universidad Católica del Norte. Calle Gustavo Le Paige 380, San Pedro de Atacama, CHILE. Email: lautanunez@netline.cl

3 Departamento de Antropología, Universidad de Chile. Ignacio Carrera Pinto 1045, Santiago, CHILE. Email: icartaje@ uchile.cl
Key words: quebrada Tulan - Archaic Formative transition - Early Formative - pastoralism - ceremonial architecture.

Recibido: enero 2006. Aceptado: julio 2006

\section{Introducción}

En distintos ambientes altoandinos, el Formativo se asocia al surgimiento de prácticas pastoralistas a partir de comunidades cazadoras recolectoras arcaicas (Núñez 1992; Yacobaccio et al. 1994; Bonnier y Rozenberg 1998; Lavallée 2000). Estas transformaciones se han identificado en la vertiente occidental de la Puna de Atacama, en el piso de quebradas intermedias (quebrada Tulan), entre la alta puna y los oasis piemontanos. Aquí se asentaron grupos arcaicos que dieron lugar a ocupaciones más estables, articulando la diversidad ambiental del transecto Tulan, entre los 2000 a 4000 m.snm. Las condiciones de ecorrefugio, en un escenario árido regional sometido a estrés ambiental (Núñez et al. 1999, 2002; Grosjean et al. 2005), favorecieron la emergencia de un locus arcaico estable de alta circunscripción social, en una escala territorial discreta, asociado a agrupaciones óptimas de baja magnitud (sensu Binford 1988). Estas condiciones permitieron la creación de un contexto sociocultural adecuado para la domesticación de camélidos, estimulando disminución de la movilidad residencial, labores de intensificación, aglomeración poblacional, relaciones complementarias de interacción macroespacial y complejidad creciente (Núñez 1994, 1999; Stein

\footnotetext{
4 Programa de Postgrado en Antropología, Universidad Católica del Norte-Universidad de Tarapacá. La Farfana 410, Maipú Santiago, CHILE. Email: c_acg@yahoo.com

5 Programa de Postgrado en Antropología, Universidad Católica del Norte-Universidad de Tarapacá. Calle Gustavo Le Paige 380, San Pedro de Atacama, CHILE. Email: pdesouza@ ucn.cl

6 Instituto de Geografía Física, Universidad de Berna. Erlachstrasse 9a, CH3012 Berna, SUIZA. Email:grosjean@ giub.unibe.ch
} 
2002). Efectivamente, la presencia de sitios arcaicos tardíos y formativos en un mismo espacio ha permitido identificar procesos de continuidad y cambio que evidencian una creciente complejidad social en el ámbito circumpuneño (Aguerre et al. 1973; Aschero 1994). En este marco, las investigaciones en el transecto Tulan se han orientado a caracterizar y comprender este proceso, a través del estudio de un conjunto de sitios vinculados con esta problemática, cuyos resultados se sintetizan en el siguiente trabajo (Figura 1, Cuadros 1 y 2).

\section{Antecedentes locales de la Fase Tilocalar}

En el asentamiento arcaico Tulan-52 se ha identificado la Fase Puripica-Tulan como el sustrato que antecede a los primeros brotes de complejidad formativa. El área nuclear de este sitio se caracteriza por la presencia de estructuras circulares y subcirculares aglomeradas, construidas con grandes bloques verticales dispuestos tanto en el piso original como sobre capas de basuras (Figuras 2 y 3 ). Hasta el momento se han obtenido seis dataciones $\mathrm{C}^{14}$ que cubren un rango temporal desde 4390 a 3860 AP, además, de una datación de 4580 AP en su periferia (Cuadros 1 y 2). Las estructuras se encuentran completamente cubiertas por depósitos estratificados derivados de actividades domésticas constituidos por fogones, restos óseos, líticos y vegetales.

Entre los materiales líticos más característicos se encuentran morteros de hueco cónico, percutores, bloques con incisiones lineales y una industria lítica tallada compuesta principalmente por puntas de proyectil foliáceas, cuchillos y raederas, además de frecuencias menores de perforadores, microperforadores, raspadores, instrumentos microlíticos, tajadores, buriles, preformas y núcleos. Las materias primas más frecuentes corresponden a rocas locales silíceas, basaltos y tobas, aunque existe una importante presencia de otras de origen foráneo como la obsidiana, la que indica cierta movilidad hacia las tierras altas. Junto a esto, hay registro de restos malacológicos del Pacífico (Oliva peruviana, Pecten purpuratus), que sugieren la existencia de contactos también hacia la costa. Los análisis arqueofaunísticos en Tulan-52 evidencian una economía basada fundamentalmente en la caza de camélidos silvestres, vicuña (Vicugna vicugna) y guanaco (Lama guanicoe). No obstante, los restos óseos y fanéreos muestran la existencia de animales domésticos (Llama, Lama glama) (Cartajena et al. 2003 Ms, 2005 Ms; Benavente 2005-6 Ms).

En este sitio se observan, además, diversos indicadores culturales que posteriormente se identifican en la Fase Tilocalar, como el patrón arquitectónico compuesto de estructuras aglomeradas subcirculares, caracterizado por el uso de grandes bloques dispuestos verticalmente, además de nichos compuestos por dintel y jambas y rocas semicanteadas en los muros (Figuras 3 y 4). A esto se agregan pozos socavados, bloques grabados con incisiones, huesos pirograbados, industria de láminas, microperforadores y elaboración de cuentas de concha y de mineral cuprífero. Asimismo, se advierte un patrón similar de formación de sitio, debido al cubrimiento de las estructuras por depósitos de basuras que alcanzan una forma monticular (Figura 3).

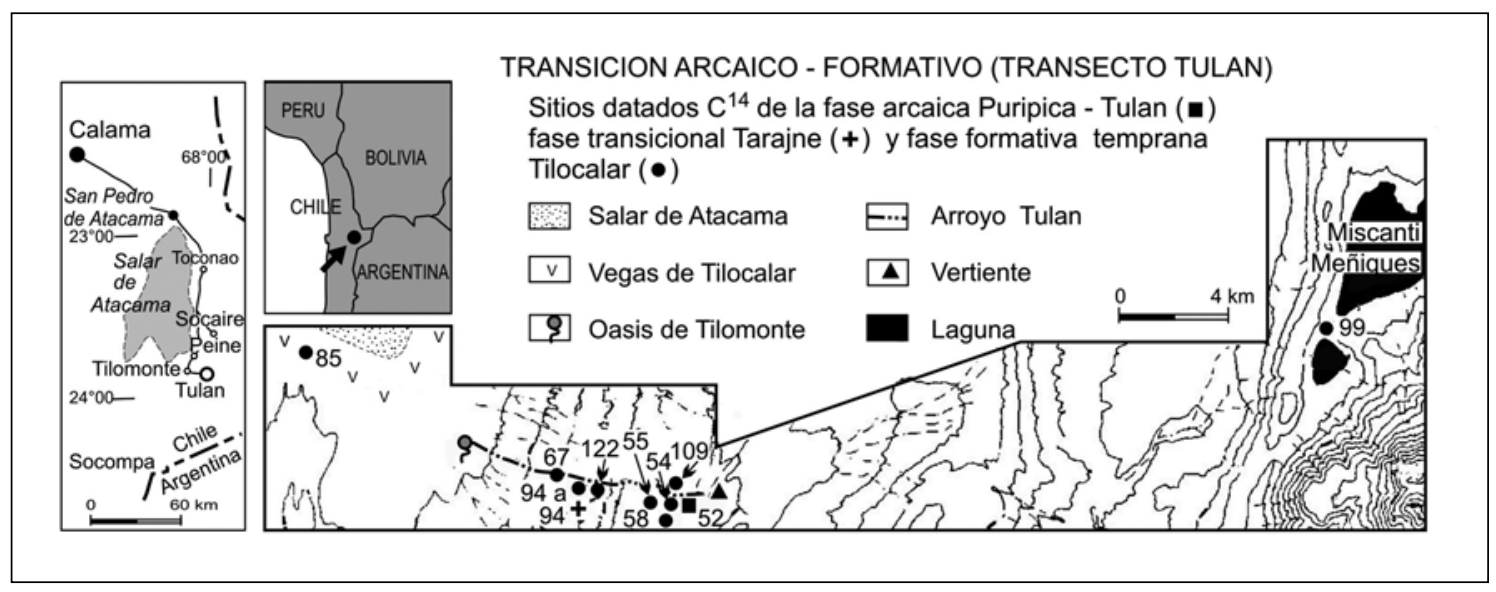

Figura 1. Transición arcaico-formativa (transecto Tulan). Ubicación de los sitios datados por $\mathrm{C}^{14}$ correspondientes a las fases arcaica tardía Puripica-Tulan, Tarajne transicional y formativa temprana Tilocalar. 


\begin{tabular}{|c|c|c|c|c|c|c|}
\hline Sitio & UTM & Altitud & Clase & $\begin{array}{c}\text { Ocupación } \\
\text { ca. } \mathbf{m}^{2}\end{array}$ & $\begin{array}{l}\text { Excavación } \\
\mathrm{m}^{2}\end{array}$ & Descripción \\
\hline TU-52 (1) & $\begin{array}{c}598877 \\
7366233\end{array}$ & $2969 \mathrm{~m}$. & $\begin{array}{l}\text { Campamento ar- } \\
\text { caico complejo }\end{array}$ & 5600 & 64 & $\begin{array}{l}\text { Asentamiento con estructuras circulares } \\
\text { aglomeradas con bases megalíticas, } \\
\text { pisos socavados, morteros cónicos, } \\
\text { cubierto con montículo estratificado. }\end{array}$ \\
\hline TU-94 (2) & $\begin{array}{c}594402 \\
7367025\end{array}$ & $2620 \mathrm{~m}$. & Aldea compleja & 600 & 10 & $\begin{array}{l}\text { Asentamiento con estructuras subcir- } \\
\text { culares aglomeradas (dos sectores), } \\
\text { aglomerados, talleres líticos y arte } \\
\text { rupestre (petroglifos). }\end{array}$ \\
\hline TU-54 (3) & $\begin{array}{c}598523 \\
7366346\end{array}$ & $2952 \mathrm{~m}$. & Aldea compleja & 2700 & 98 & $\begin{array}{l}\text { Templete central con nichos rodeado } \\
\text { de estructuras subcirculares con bases } \\
\text { megalíticas, cubierto con montículo } \\
\text { estratificado. }\end{array}$ \\
\hline TU-122 (3) & $\begin{array}{c}594850 \\
7366850\end{array}$ & $2680 \mathrm{~m}$. & Aldea compleja & 15000 & 4 & $\begin{array}{l}\text { Asentamiento con estructuras disper- } \\
\text { sas y aglomeradas subcirculares, con } \\
\text { nichos aislados y bodegas reducidas } \\
\text { agregadas al exterior. Asociado a } \\
\text { talleres líticos. }\end{array}$ \\
\hline TU-85 (3) & $\begin{array}{c}584802 \\
7372632\end{array}$ & $2318 \mathrm{~m}$ & Aldea compleja & 2500 & 11 & $\begin{array}{l}\text { Asentamiento con estructuras margi- } \\
\text { nales y denso depósito monticulado. } \\
\text { Incluye sector con inhumaciones de } \\
\text { neonatos. }\end{array}$ \\
\hline TU-55 (3) & $\begin{array}{c}597321 \\
7366803\end{array}$ & $2680 \mathrm{~m}$ & $\begin{array}{l}\text { Cueva ocupada- } \\
\text { arte rupestre }\end{array}$ & 80 & 9 & $\begin{array}{l}\text { Cueva con secuencia del Formativo } \\
\text { Temprano a Desarrollo Regional Tardío. } \\
\text { Incluye arte rupestre (petroglifos). }\end{array}$ \\
\hline TU-67 (3) & $\begin{array}{r}594134 \\
7378278\end{array}$ & $2600 \mathrm{~m}$. & $\begin{array}{l}\text { Cueva ocupada- } \\
\text { arte rupestre }\end{array}$ & $\begin{array}{c}21 \\
\text { (intra sitio) } \\
62 \\
\text { (extra sitio) }\end{array}$ & 6 & $\begin{array}{l}\text { Cueva con secuencia arcaica temprana } \\
\text { a Formativo Temprano; incluye picto- } \\
\text { grafìas y taller lítico exterior. }\end{array}$ \\
\hline TU-109 (3) & $\begin{array}{r}599097 \\
7366462\end{array}$ & $2950 \mathrm{~m}$ & $\begin{array}{l}\text { Abrigo ocupado- } \\
\text { arte rupestre }\end{array}$ & 7.5 & 3.5 & $\begin{array}{l}\text { Abrigo con secuencia arcaica temprana } \\
\text { a Formativo Temprano. Asociado a } \\
\text { paneles con arte rupestre (petroglifos } \\
\text { Taira-Tulan). }\end{array}$ \\
\hline TU-58 (3) & $\begin{array}{c}598520 \\
7366400\end{array}$ & $2700 \mathrm{~m}$ & Cementerio & 400 & 8 & $\begin{array}{l}\text { Inhumaciones bajo rocas decúbito } \\
\text { dorsal con extremidades flectadas y } \\
\text { sentados asociados a postes. }\end{array}$ \\
\hline TU-99 (3) & $\begin{array}{r}622397 \\
7621461\end{array}$ & $4000 \mathrm{~m}$ & $\begin{array}{l}\text { Campa me n to } \\
\text { post-arcaico }\end{array}$ & 225 & 3 & $\begin{array}{l}\text { Campamento en cuenca lacustre con } \\
\text { depósito estratificado con componentes } \\
\text { formativos tempranos sobre ocupación } \\
\text { arcaica tardía. }\end{array}$ \\
\hline
\end{tabular}

Cuadro 1. Síntesis descriptiva de sitios con dataciones $\mathrm{C}^{14}$ correspondientes a las fases Puripica-Tulan (1), Tarajne (2) y Tilocalar (3).

Otra ocupación con dataciones de la Fase Puripica-Tulan, se registró en el sitio Tulan-122, correspondiente a un asentamiento emplazado en el borde sur del tramo medio de la quebrada. Aquí se encuentra un conjunto de estructuras circulares agrupadas hacia el sector este del sitio. Si bien no presenta densos depósitos como Tulan-52, es notoria la conformación de un pequeño montículo. Se excavó una unidad al interior de un recinto, donde se obtuvo una fecha de 4120 AP en asociación a abundante material lítico, correspondiente principalmente a láminas de toba y restos óseos. No obstante, se observa un sector más extenso, donde se detectaron ocupaciones formativas tempranas, lo que indica un uso reiterativo de un mismo espacio por poblaciones de las fases Puripica-Tulan y Tilocalar. 


\begin{tabular}{|c|c|c|c|c|c|c|c|c|c|c|c|c|c|c|c|c|c|c|c|c|c|}
\hline 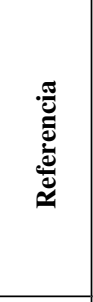 & 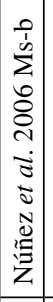 & 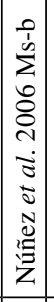 & 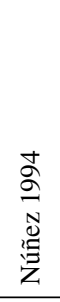 & 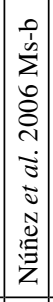 & 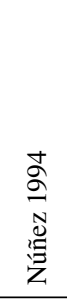 & 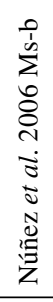 & 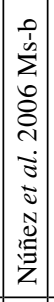 & 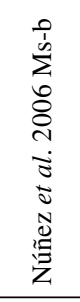 & 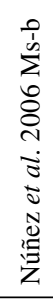 & 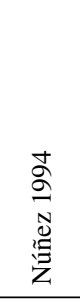 & 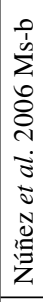 & 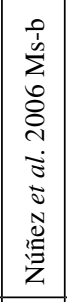 & 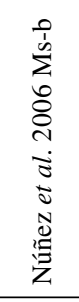 & 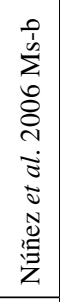 & 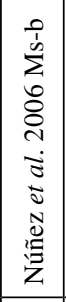 & 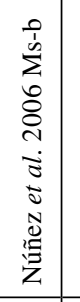 & 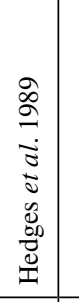 & 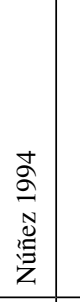 & 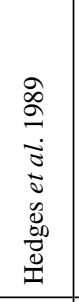 & 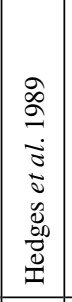 & 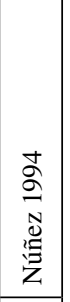 \\
\hline 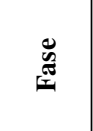 & 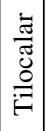 & 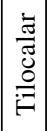 & 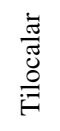 & 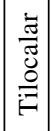 & 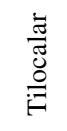 & 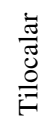 & 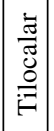 & 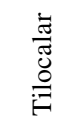 & 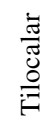 & 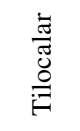 & $\begin{array}{l}\frac{\vec{\Xi}}{\tilde{J}} \\
\frac{0}{\sigma}\end{array}$ & 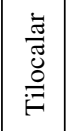 & 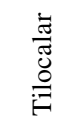 & $\begin{array}{l}\frac{\vec{\Xi}}{\tilde{J}} \\
\stackrel{0}{\rightleftarrows} \\
\vec{F}\end{array}$ & 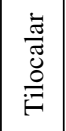 & $\begin{array}{l}\frac{\tilde{\Xi}}{\tilde{J}} \\
\frac{0}{F} \\
\vec{F}\end{array}$ & 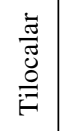 & 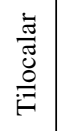 & 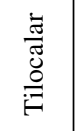 & 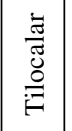 & 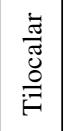 \\
\hline 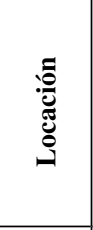 & \begin{tabular}{|c|}
0 \\
0 \\
0 \\
0 \\
0 \\
0 \\
5 \\
5 \\
\\
\end{tabular} & 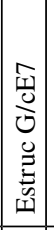 & 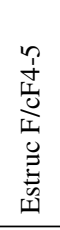 & 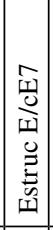 & 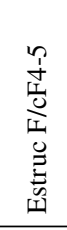 & 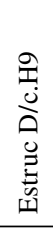 & 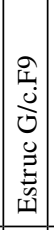 & 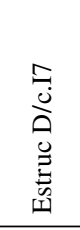 & 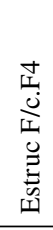 & 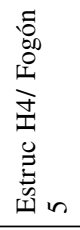 & 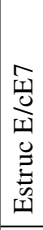 & 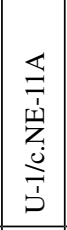 & 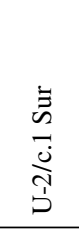 & 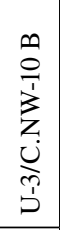 & 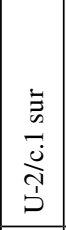 & 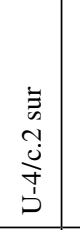 & $\stackrel{m}{0}$ & $\tilde{U}_{0}$ & $\stackrel{\cong}{0}$ & $\stackrel{\oplus}{0}$ & $\bigcup_{ن}^{J}$ \\
\hline 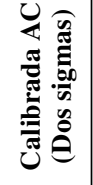 & $\mid \begin{array}{l}8 \\
0 \\
e \\
o \\
0 \\
1 \\
1\end{array}$ & $\mid \begin{array}{l}0 \\
0 \\
0 \\
\tilde{z} \\
\tilde{2} \\
1\end{array}$ & 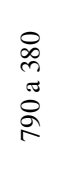 & 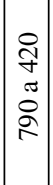 & $\begin{array}{l}\stackrel{2}{2} \\
\text { స్ } \\
\stackrel{0}{0} \\
\infty\end{array}$ & 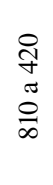 & 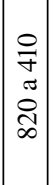 & 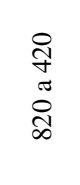 & 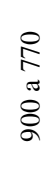 & 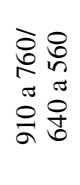 & 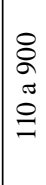 & 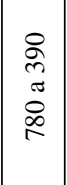 & 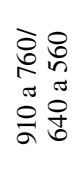 & 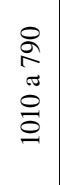 & 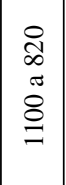 & 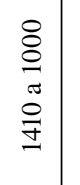 & 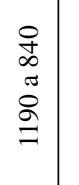 & 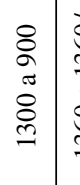 & 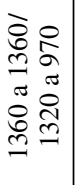 & $\begin{array}{l}0 \\
\tilde{O} \\
\sigma \\
\delta \\
8 \\
\dot{O}\end{array}$ & 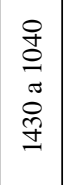 \\
\hline 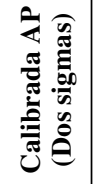 & 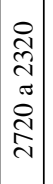 & 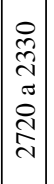 & 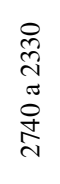 & 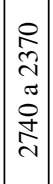 & 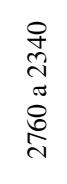 & 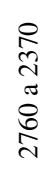 & 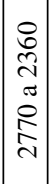 & 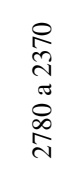 & 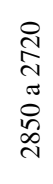 & 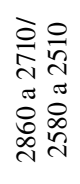 & 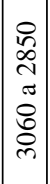 & 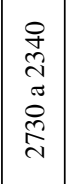 & 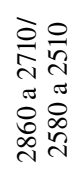 & 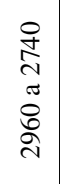 & 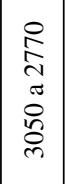 & 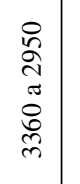 & 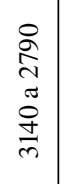 & \begin{tabular}{l|l}
0 & \\
$\infty$ & \\
$\sim$ & \\
0 & \\
0 & \\
0 & \\
&
\end{tabular} & 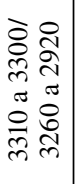 & 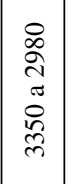 & 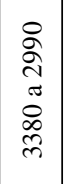 \\
\hline 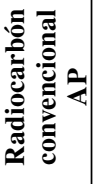 & 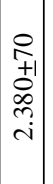 & $\left|\begin{array}{c}0 \\
0 \\
+1 \\
0 \\
\text { iे } \\
\end{array}\right|$ & \begin{tabular}{l}
$\stackrel{8}{1}$ \\
$\stackrel{+}{1}$ \\
\multirow{2}{*}{}
\end{tabular} & 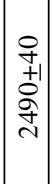 & 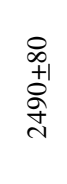 & $\begin{array}{l}8 \\
\text { +1 } \\
0 \\
0 \\
\end{array}$ & 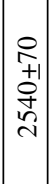 & 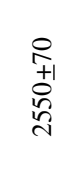 & $\begin{array}{l}8 \\
\text { + } \\
+ \\
0 \\
0 \\
\text { N }\end{array}$ & 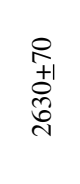 & 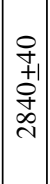 & $\mid$\begin{tabular}{l}
8 \\
0 \\
+1 \\
+ \\
\multirow{g}{1}{} \\
1
\end{tabular} & 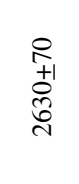 & 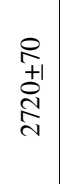 & 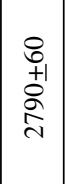 & $\begin{array}{l}2 \\
+1 \\
+ \\
0 \\
\text { ते }\end{array}$ & 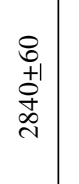 & $\begin{array}{l}\text { o } \\
+1 \\
0 \\
\text { वे } \\
\text { in }\end{array}$ & $\begin{array}{l}8 \\
\text { + } \\
+1 \\
+1 \\
\text { ì }\end{array}$ & $\begin{array}{l}8 \\
0 \\
+1 \\
0 \\
8 \\
0\end{array}$ & 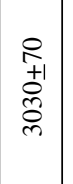 \\
\hline 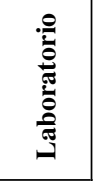 & 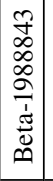 & 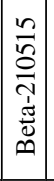 & 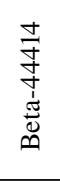 & 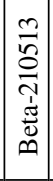 & 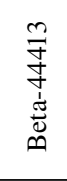 & $\begin{array}{l}\frac{1}{\pi} \\
\frac{2}{2} \\
\frac{\pi}{0} \\
\infty\end{array}$ & 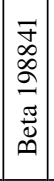 & 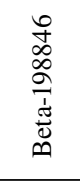 & 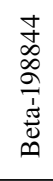 & 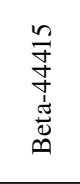 & 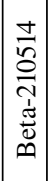 & 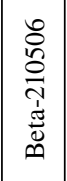 & 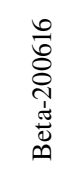 & 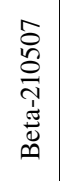 & 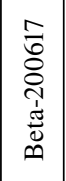 & $\begin{array}{l}\infty \\
0 \\
0 \\
\stackrel{N}{1} \\
\stackrel{0}{0} \\
\infty\end{array}$ & 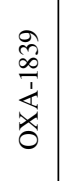 & $\begin{array}{l}\hat{\infty} \\
\frac{\infty}{\tilde{J}} \\
\stackrel{0}{\infty}\end{array}$ & $\underset{\substack{\infty \\
\infty}}{\stackrel{\infty}{\dot{亠}}}$ & $\begin{array}{l}\vec{F} \\
\frac{\infty}{+} \\
\dot{x} \\
0 \\
0\end{array}$ & 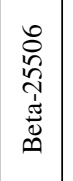 \\
\hline 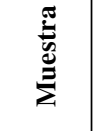 & 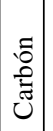 & $\mid$\begin{tabular}{l|}
0 \\
0 \\
0 \\
$\tilde{z}$ \\
0
\end{tabular} & 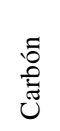 & 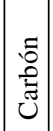 & 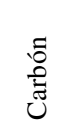 & 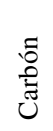 & 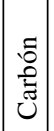 & 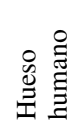 & 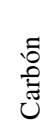 & 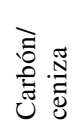 & 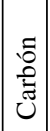 & 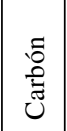 & 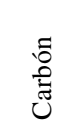 & 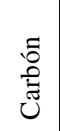 & 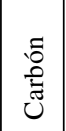 & $\begin{array}{l}\tilde{0} \\
\text { हैँ } \\
\text { Uే }\end{array}$ & $\stackrel{0}{0}$ & 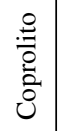 & $\stackrel{0}{\stackrel{0}{3}}$ & $\stackrel{\infty}{\stackrel{0}{0}}$ & 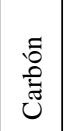 \\
\hline 䓂 & 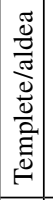 & 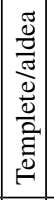 & 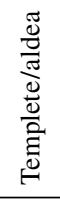 & 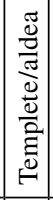 & 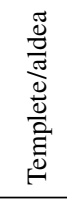 & 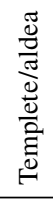 & 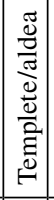 & 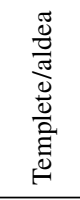 & 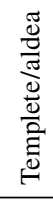 & 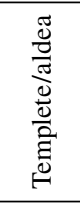 & 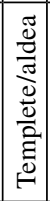 & 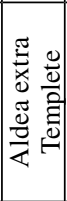 & 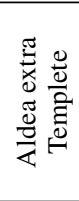 & 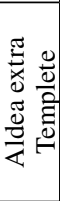 & 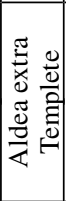 & 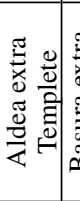 & $\begin{array}{ll}\widetilde{J} \\
0\end{array}$ & 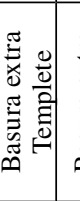 & 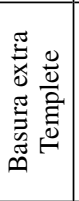 & 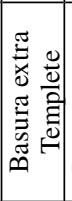 & 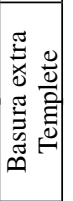 \\
\hline 竞 & $\mid \begin{array}{l}0 \\
5 \\
2 \\
0\end{array}$ & 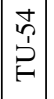 & 菅 & 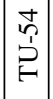 & 常 & 菅 & 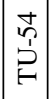 & 志 & 常 & 常 & 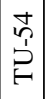 & 菅 & 志 & 点 & 点 & 菢 & 点 & 菅 & 常 & 常 & 点 \\
\hline$i$ & -1 & $N$ & $m$ & r & in & 0 & $r$ & $\infty$ & $a$ & 은 & $=$ & $\simeq$ & 9 & \pm & $\stackrel{2}{2}$ & $\stackrel{\varrho}{ }$ & $=$ & $\stackrel{\infty}{\stackrel{1}{2}}$ & 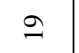 & ¿ & $\bar{\lambda}$ \\
\hline
\end{tabular}




\begin{tabular}{|c|c|c|c|c|c|c|c|c|c|c|c|c|c|c|c|c|c|c|c|c|}
\hline 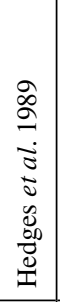 & 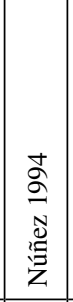 & 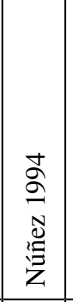 & 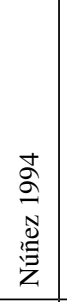 & 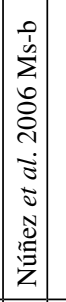 & 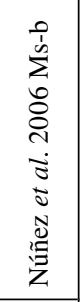 & 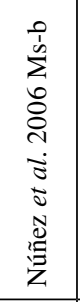 & 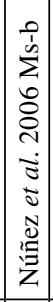 & 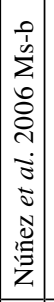 & 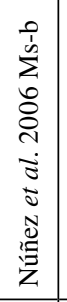 & 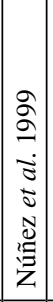 & 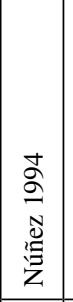 & 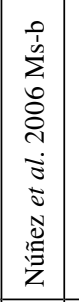 & 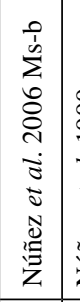 & 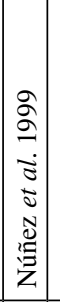 & 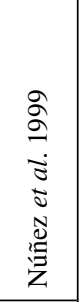 & 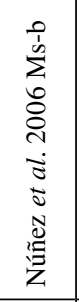 & 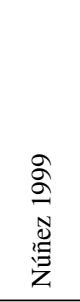 & 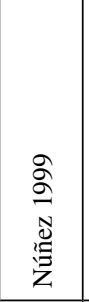 & 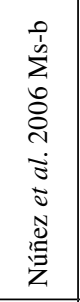 & 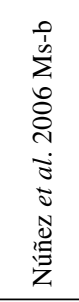 \\
\hline $\begin{array}{l}\frac{\tilde{\Xi}}{\tilde{J}} \\
\frac{0}{F} \\
\vec{F}\end{array}$ & $\begin{array}{l}\text { 丞 } \\
\stackrel{0}{E}\end{array}$ & 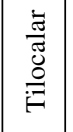 & $\begin{array}{l}\stackrel{\vec{\Xi}}{\tilde{J}} \\
\stackrel{\circ}{\exists}\end{array}$ & 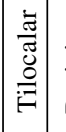 & 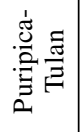 & $\begin{array}{l}\text { 丞 } \\
\stackrel{\circ}{E}\end{array}$ & 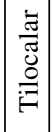 & 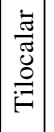 & 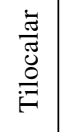 & 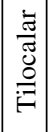 & 䔍 & 䔍 & . & 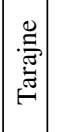 & 鹈: & 离 & : & 密 & 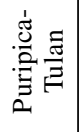 & 离离 \\
\hline త্ & $\begin{array}{l}\vec{I} \\
\stackrel{\vec{v}}{0} \\
\stackrel{0}{*}\end{array}$ & $\overbrace{}^{m}$ & $\vec{u}$ & 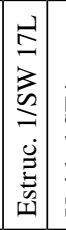 & 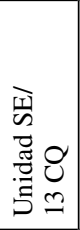 & $\stackrel{\infty}{ن}$ & $\begin{array}{c}0 \\
ن\end{array} \mid$ & $\begin{array}{l}\infty \\
ن\end{array}$ & 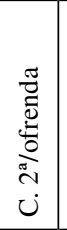 & 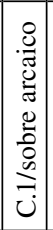 & 离 & 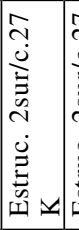 & 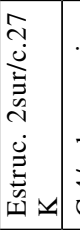 & 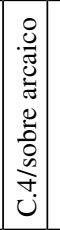 & $\begin{array}{l}3 \\
\text { s } \\
n \\
0 \\
0\end{array}$ & $\begin{array}{l}3 \\
0 \\
0 \\
0 \\
0 \\
0\end{array}$ & $\tilde{m}$ & $\tilde{\rho}$ & $\hat{\tilde{\rho}}$ & $\begin{array}{l}\hat{v} \\
\dot{j}\end{array}$ \\
\hline 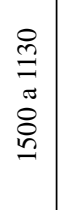 & 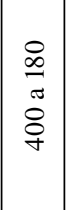 & 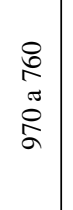 & 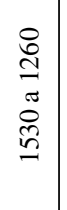 & $\left|\begin{array}{l}0 \\
0 \\
0 \\
\sigma \\
0 \\
0 \\
\simeq\end{array}\right|$ & 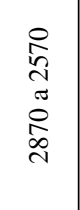 & 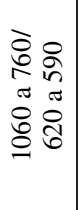 & 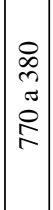 & 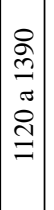 & 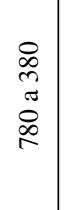 & 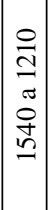 & $\begin{array}{l}0 \\
\infty \\
\tilde{\sigma} \\
0 \\
\stackrel{\Xi}{ \pm}\end{array}$ & 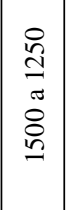 & 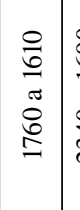 & 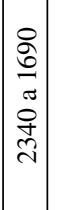 & 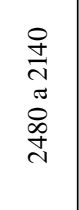 & 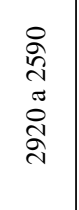 & 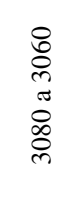 & 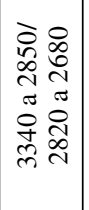 & 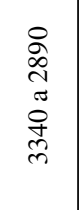 & 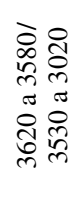 \\
\hline 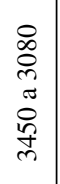 & 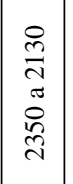 & 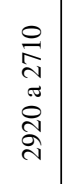 & 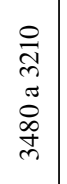 & 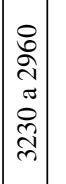 & 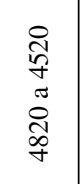 & 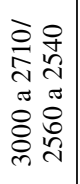 & 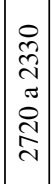 & 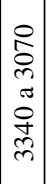 & 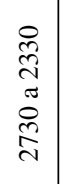 & 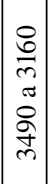 & 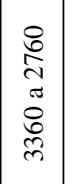 & 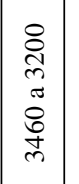 & 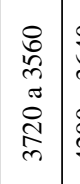 & 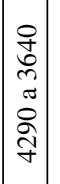 & 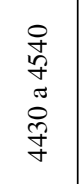 & 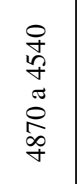 & 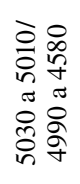 & 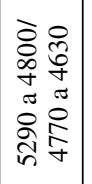 & 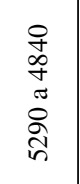 & 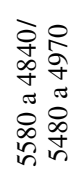 \\
\hline 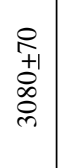 & 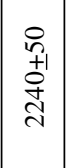 & 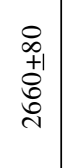 & $\begin{array}{l}\stackrel{p}{a} \\
+1 \\
+ \\
\dot{d} \\
m\end{array}$ & $\left|\begin{array}{l}0 \\
9 \\
+1 \\
0 \\
⿱ 亠 䒑 \\
i\end{array}\right|$ & 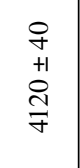 & $\begin{array}{l}8 \\
\stackrel{1}{+1} \\
\stackrel{1}{8} \\
\stackrel{\lambda}{2}\end{array}$ & 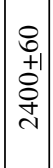 & $\left|\begin{array}{c}0 \\
9 \\
+1 \\
0 \\
0 \\
0\end{array}\right|$ & \begin{tabular}{l}
$\stackrel{P}{2}$ \\
+1 \\
$\stackrel{0}{+}$ \\
\multirow{d}{d}{}
\end{tabular} & $\mid \begin{array}{c}0 \\
\infty \\
0 \\
+1 \\
+ \\
m \\
m\end{array}$ & 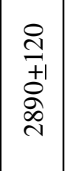 & $\begin{array}{l}8 \\
0 \\
+1 \\
\stackrel{ }{\Rightarrow}\end{array}$ & \begin{tabular}{l|l}
$o$ & \\
$q$ & \\
+1 & \\
8 & \\
9 &
\end{tabular} & 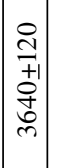 & $\begin{array}{l}0 \\
0 \\
+1 \\
0 \\
0 \\
\infty \\
\infty\end{array}$ & 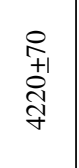 & 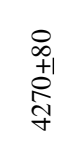 & $\begin{array}{l}8 \\
\frac{1}{+1} \\
0 \\
⿱ 亠+ \\
9\end{array}$ & 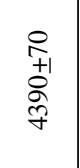 & 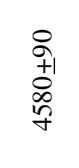 \\
\hline 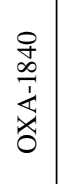 & $\begin{array}{l}\hat{\infty} \\
\tilde{\pi} \\
\tilde{D} \\
\tilde{\tilde{D}} \\
\infty \\
\infty\end{array}$ & 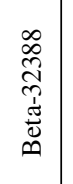 & 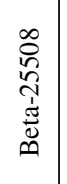 & 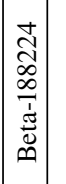 & 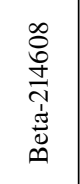 & 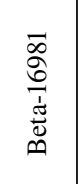 & 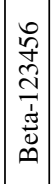 & 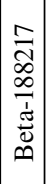 & 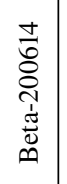 & 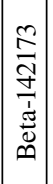 & 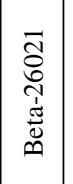 & 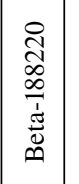 & 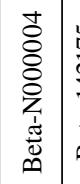 & 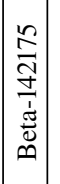 & 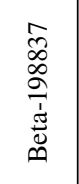 & 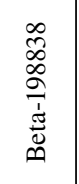 & 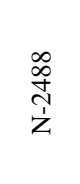 & $\begin{array}{l}\stackrel{\infty}{\infty} \\
\stackrel{+}{Z} \\
\dot{z}\end{array}$ & 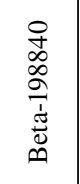 & 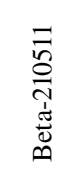 \\
\hline$\stackrel{n}{\stackrel{n}{\exists}}$ & 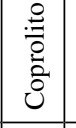 & 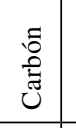 & 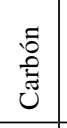 & 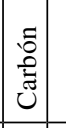 & 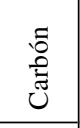 & 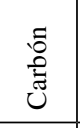 & $\begin{array}{l}0 \\
0 \\
0 \\
0 \\
0 \\
\end{array}$ & 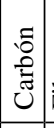 & 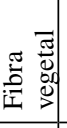 & \begin{tabular}{|c|}
0 \\
0 \\
0 \\
0 \\
0 \\
\end{tabular} & 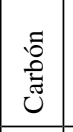 & 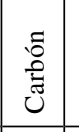 & . & 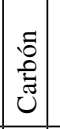 & 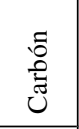 & 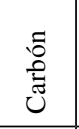 & 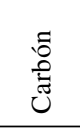 & 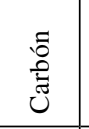 & $\begin{array}{l}\tilde{0} \\
\text { ठีँ } \\
\tilde{U}\end{array}$ & 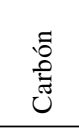 \\
\hline 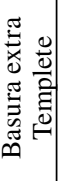 & 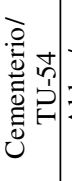 & 矛 & 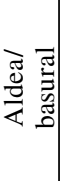 & $\frac{\pi}{\frac{\pi}{\pi}}$ & $\frac{\frac{\pi}{\pi}}{4}$ & $\frac{\mathbb{J}}{\mathbb{\pi}}$ & Uీ & 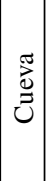 & $\begin{array}{l}\stackrel{8}{\circ} \\
\stackrel{0}{0} \\
\frac{0}{4}\end{array}$ & 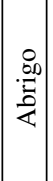 & 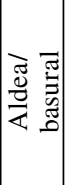 & $\frac{\pi}{\frac{\pi}{2}}$ & $\frac{\mathbb{J}}{\mathbb{Z}}$ & 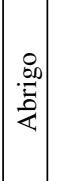 & 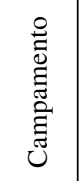 & 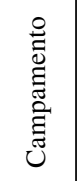 & 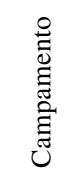 & 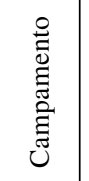 & 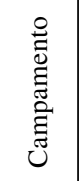 & 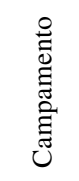 \\
\hline 葛 & 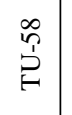 & 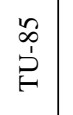 & 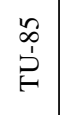 & 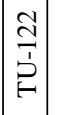 & ปี & 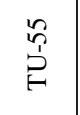 & $\begin{array}{l}n \\
n \\
p \\
p\end{array}$ & 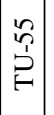 & $\frac{8}{\frac{8}{2}}$ & 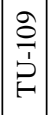 & 蛋 & 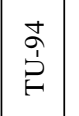 & 吉 & 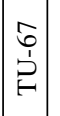 & 芯 & 令 & 令 & 令 & 瓷 & 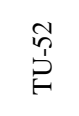 \\
\hline$\tilde{N}$ & $\tilde{\lambda}$ & $\stackrel{\forall}{\sim}$ & 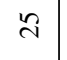 & i & $\hat{\sim}$ & $\stackrel{\infty}{\sim}$ & ते & i্ & $\bar{m}$ & $\tilde{m}$ & $m$ & ম & $m$ & $\stackrel{m}{\infty}$ & $\bar{m}$ & $\stackrel{\infty}{m}$ & ले & q & $F$ & I \\
\hline
\end{tabular}




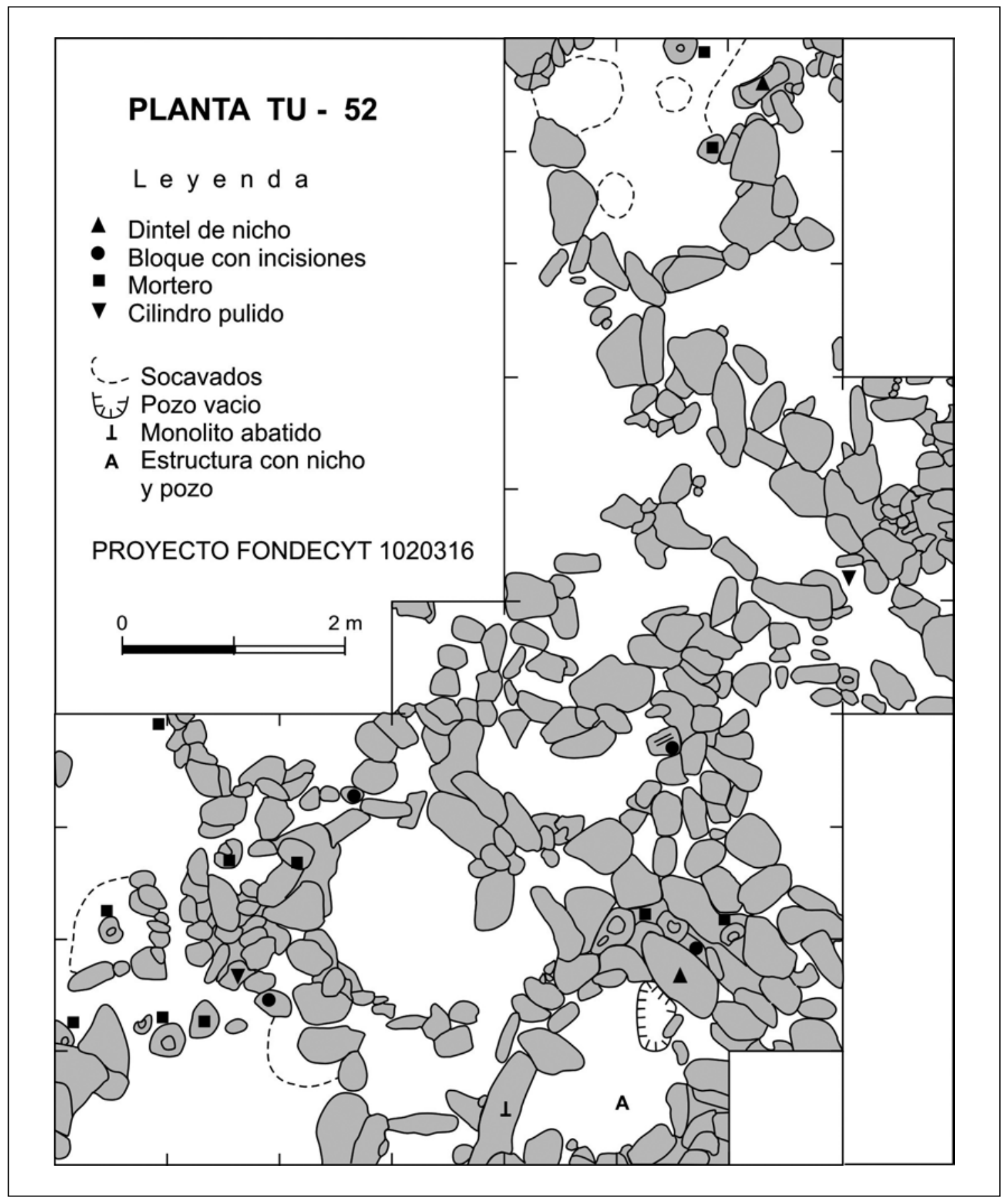

Figura 2. Planta del campamento arcaico tardío Tulan-52.

Las dataciones más tardías obtenidas de Tulan-52 (y también de otros sitios del Arcaico Tardío regional) no han superado hasta ahora los $3800 \mathrm{AP}$, lo que establece un hiato cronológico de unos 600 años con las dataciones más tempranas obtenidas de los sitios de la Fase Tilocalar (alrededor del 3100-3200 AP).
Este vacío ha comenzado a ser cubierto a partir de los recientes datos cronológicos obtenidos del sitio Tulan-94, el que a base de sus fechas absolutas y a sus contextos, sugieren la posibilidad de definir una fase transicional entre el Arcaico Tardío y el Formativo Temprano, la cual hemos denominado 


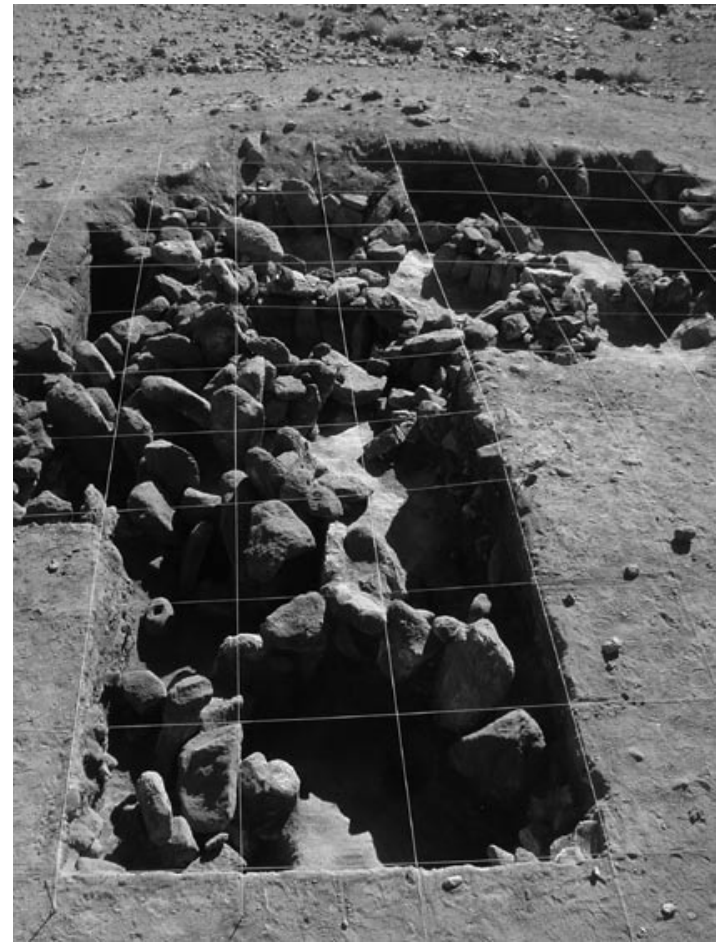

Figura 3. Vista general del campamento arcaico tardío Tulan-52.

Fase Tarajne. En efecto, del sitio Tulan-94 fueron obtenidas dataciones de 3400 AP (principio de ocupación) y 3110 AP (final de ocupación), las cuales cubren en forma relativamente significativa el hiato cronológico referido. Lo anterior sugiere que entre aproximadamente los 3500 y los 3200 AP, se desarrolla en quebrada Tulan un patrón de asentamiento diferente, no ocupándose los mismos sitios que se utilizaron inmediatamente antes y después de este lapso temporal.

El sitio Tulan-94, se compone de dos conjuntos contiguos de estructuras circulares y subcirculares, con un total de 19 recintos habitacionales y al parecer otros de almacenamiento. En este sitio se registraron en superficie materiales líticos, cobre triturado, fogones expuestos, implementos de molienda y escasa cerámica de filiación temprana, correspondiente a Los Morros B (Sinclaire et al. 1998). Las excavaciones permitieron registrar depósitos de hasta $70 \mathrm{~cm}$ de profundidad, que incluyen material lítico, óseo, vegetales, cuentas, fragmentos de conchas del Pacífico, coprolitos y guano de camélido, cordelería y fibras de origen animal, además de un resto de lámina de oro y un fragmento cerámico, correspondiente a Los Morros B2 (Uribe 2006).

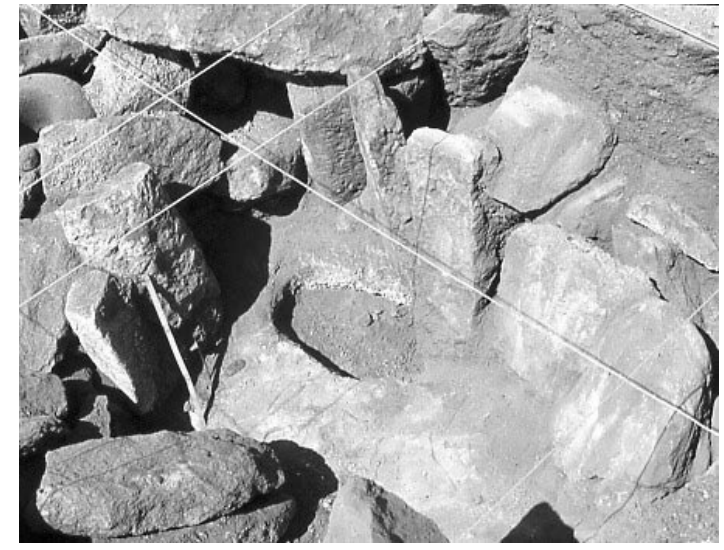

Figura 4. Estructura con nicho y pozo vacío en el piso del campamento arcaico tardío Tulan-52.

El registro lítico da cuenta de una mayor frecuencia de puntas de proyectil foliáceas, artefactos multifuncionales, raederas, raspadores, y frecuencias menores de preformas bifaciales, cuchillos, perforadores, buriles, tajadores y puntas pedunculadas. Al respecto, a partir de estas evidencias y otros indicadores, se advierte el carácter transicional del sitio, puesto que presenta componentes materiales correspondientes a las fases Puripica/Tulan y Tilocalar. De esta forma, desde la primera continúan los morteros de hueco cónico, el dominio de puntas foliáceas y un patrón arquitectónico circular aglomerado. Por otra parte, como elementos propios de la Fase Tilocalar se identifica un predominio de microperforadores por sobre perforadores de mayor tamaño, oro laminado, cerámica y puntas con pedúnculo diferenciado. Además, un bloque en el borde del asentamiento presenta diseños de camélidos grabados con un estilo que parece ser transicional entre Kalina-Puripica del Arcaico Tardío y Taira-Tulan del Formativo Temprano (Berenguer y Cáceres 1989; Núñez et al. 2006a).

Una ocupación relativamente contemporánea a Tulan94 se registró en el Estrato II de la cueva Tulan-67, datado a los 3640 AP (Cuadro 2), con materiales culturales correspondientes a perforadores, lascas de uso expeditivo, instrumentos de molienda, pigmento rojo, coprolitos, vellones, hilados y restos óseos de camélidos. A diferencia de Tulan-94, la baja densidad de materiales apunta a que se trataría de un asentamiento de uso efímero vinculado a esta fase transicional.

La investigación aún incipiente de los registros culturales de la Fase Tarajne hace aún difícil ofre- 
cer definiciones más precisas sobre los patrones económicos y culturales que caracterizarían a este momento transicional. Sin embargo, es claro que existió un momento de transición en el que aún se siguen utilizando varios tipos de instrumentos de origen arcaico, pero en el que, a la vez, ya se están comenzando a introducir ciertos atributos que después serán típicos de la Fase Tilocalar. Se espera, por una parte, que futuras investigaciones en el sitio Tulan-94 permitan ampliar el registro y, por otra, identificar nuevos sitios transicionales que posibiliten una mejor comprensión y contextualización de esta fase.

\section{La Fase Tilocalar}

La Fase Tilocalar puede definirse a partir de un conjunto de indicadores culturales que señalan los inicios del Formativo. Corresponde al surgimiento de la vida aldeana y del pastoralismo, junto con una intensificación y ampliación de otras prácticas productivas, asociadas a un marcado énfasis de expresiones rituales. En la quebrada de Tulan, el rango cronológico de esta fase se ha determinado entre los 3080 a $2380 \mathrm{AP}$, a partir de un total de 35 dataciones $\mathrm{C}^{14}$ registradas en seis sitios ubicados a los largo del transecto, los que serán reseñados a continuación (Cuadros 1 y 2).

\section{Tulan-109}

Se trata de un refugio discreto asociado a dos paneles con arte rupestre del estilo Taira-Tulan (Gallardo et al. 1999; Berenguer 2004; Núñez et al. 2006a). Sobre un depósito arcaico temprano se identificó un estrato formativo, datado por radiocarbón a los 3140 AP, el cual contiene fogones, restos vegetales, cordelería en fibras de origen animal y vegetal, restos óseos de camélidos y de fauna menor, plumas, mineral de cobre triturado, fibras de origen animal, raederas, lascas de uso expeditivo y desechos de talla en sílice y obsidiana (Cuadros 1 y 2).

En la parte superior del estrato formativo se identificó un contexto excepcional, consistente en una ofrenda correspondiente a un "paquete" de estera amarrado con cordeles de lana teñidos. En su interior, se encontraron cuatro propulsores óseos confeccionados sobre radioulnas de camélidos; un componente medial de dardo de madera, con abultamiento para estabilización; tres piezas similares a "peines" de madera y dos ornamentos de hueso con recortes laterales y bordes policromados, similares a "plumas" (Figura 5). Estos últimos artefactos guardan estrecha similitud con aquellos registrados en un cementerio de Guatacondo, donde se encontraron insertos en turbantes sobre cráneos, con una datación radiocarbónica contemporánea a la Fase Tilocalar (Meighan 1980).

La estera fue datada por radiocarbón en 2410 AP, lo que indicaría una relación entre las prácticas de caza mediante el uso de propulsores y los diseños que representarían camélidos domésticos característicos del estilo Taira-Tulan (Gallardo y Yacobaccio 2005). La presencia de propulsores podría explicarse como una pervivencia arcaica, no sólo en el ámbito de las estrategias de subsistencia, sino también en un ámbito ritual al interior de las sociedades formativas, aun cuando ya se incrementaba el uso del arco y flecha (de Souza 2006).

\section{Tulan-55}

Este sitio corresponde a una cueva más amplia, de unos $7 \mathrm{~m}$ de frente y $10 \mathrm{~m}$ de fondo, con ocupaciones desde el Formativo Temprano al Intermedio Tardío, donde se observa una importante concentración de arte rupestre, aunque si bien no es clara la presencia de estilos formativos a excepción de escasos diseños de incisiones lineales. Los depósitos culturales superiores han sido alterados por ocupaciones subactuales, sin embargo, los estratos inferiores (E-VII y VIII) han permanecido intactos. Desde aquí se han obtenido dataciones de 3010, 2700 y $2400 \mathrm{AP}$, asociadas a restos vegetales, faunísticos y líticos. Los restos vegetales consisten en hojas y granos de maíz, semillas de cucurbitáceas, chañar y algarrobo, tubérculos, raíces de Scirpus sp., Opuntia

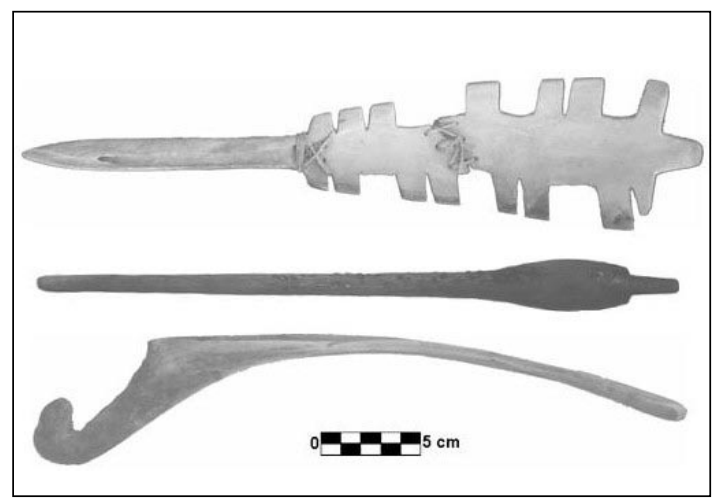

Figura 5. Elementos de la ofrenda registrada en el alero Tulan-109. Superior: Ornamento de hueso ("pluma"). Centro: Componente medial de dardo. Inferior: Propulsor de hueso. 
sp., cortadera, Festuca sp. y Stipa sp. (Popper 1987), además de cordelería en fibra vegetal y cestería en espiral. Los restantes materiales culturales incluyen fragmentos de objetos de cuero (p.e., sandalias), artefactos líticos de uso expeditivo, microperforadores, conanas o instrumentos de molienda de carácter inmóvil cuya concavidad es más ancha que profunda (sensu Cornejo 1991), manos, pigmento rojo, puntas pedunculadas, cobre triturado, una cuenta discoidal, láminas de cobre fundido y martillado, plumas de aves tropicales, conchas del Pacífico y del oriente yungueño, además de cerámica de los tipos Los Morros, Loa Café Alisado y San Pedro Negro Pulido (Kalazich $2006 \mathrm{Ms}$ ). Por otra parte, se han identificado restos óseos de camélidos de ambos grupos de tamaño (vicuña y llama/guanaco $)^{7}$, cordelería, textilería e hilados teñidos de fibra animal, vellones, cueros curtidos y fecas de camélido, lo que permite postular una fuerte orientación del asentamiento hacia actividades de carácter pecuario. Al respecto, un fragmento de piso compacto de corral encontrado al inicio de ocupación podría establecer relaciones con mantención de ganado al pie del acantilado junto al sitio donde se observan corrales modernos.

\section{Tulan-85}

En el borde del Salar de Atacama, en las vegas del piso inferior del transecto, se identificó una extensa ocupación cubierta por depósitos de basura que generaron un amplio montículo. La excavación realizada permitió exponer un perfil que alcanza los $2 \mathrm{~m}$ de profundidad, con una alta densidad de restos culturales (Núñez 1992, 1995). Entre los materiales recuperados se destacan restos vegetales, como junquillo (Schoenoplectus americanus), Cyperacea sp., Atriplex madariagae y Opuntia (Holden 1991; Bueno 2004 Ms), además de abundantes artefactos líticos tallados y de molienda, fibras de origen animal, coprolitos y restos óseos de camélidos (Cuadro 2).

En la base de la excavación se registraron bloques correspondientes a bordes de estructuras, junto

\footnotetext{
A través de la osteometría es posible segregar dos grupos de tamaño: los camélidos pequeños (vicuñas) y los grandes (guanacos). No obstante, en contextos donde se registran tanto animales silvestres como domésticos, en el grupo pequeño podrían encontrarse tanto vicuñas como alpacas (vicuña/alpaca) y en el grande guanacos y llamas (guanaco/llama) (Wing 1972).
}

a cuatro inhumaciones de neonatos sin ofrendas, dispuestos entre lajas verticales y horizontales. Uno de los cuerpos presenta el cráneo envuelto por un turbante de hilados, rasgo que es recurrente durante el Formativo en los valles de Arica, Tarapacá, Guatacondo y San Pedro de Atacama (Meighan 1980; Agüero 1994). Sin embargo, si bien se registra una importante densidad de neonatos, aún no se ha identificado la sofisticación de las ofrendas de Tulan-54. Asociado a estas inhumaciones, se obtuvo una datación en un depósito a comienzos de ocupación de 3140 AP. En un estrato más alto, datado a los $2660 \mathrm{AP}$, se excavó un pozo circular que contenía otra inhumación de infante asociado a una cuchara de cobre de mango corto, cuentas discoidales de conchas del Pacífico y tubulares de crisocola, restos de Choromytilus y dos escápulas de camélido. En este mismo nivel, se determinó la presencia de cucurbitáceas y marlos de maíz, probablemente cultivados en Tilomonte, el oasis más cercano, puesto que las vegas de Tilocalar no habrían favorecido las actividades hortícolas, sino únicamente aquellas de forrajeo.

Los materiales líticos y cerámicos recuperados se asemejan a los de Tulan-54, puesto que se observan principalmente microperforadores, puntas pedunculadas y cuchillos, además de frecuencias menores de puntas foliáceas, muescas, raspadores, raederas, conanas y manos. Del mismo modo, se encontraron lascas de uso expeditivo y desechos de talla en rocas silíceas, obsidiana y toba. La cerámica corresponde a fragmentos grises o café alisados con desgrasantes gruesos y otros cafés, negros y grises pulidos, gruesos y delgados, destacándose algunos gruesos corrugados, con impresiones de uña y con excisos discoidales pequeños. Los restos óseos, al igual que en otros sitios analizados, dan cuenta de dos grupos de tamaño para los camélidos, lo que sugiere la explotación al menos de vicuñas y guanaco/llama.

\section{Tulan-122}

El sector correspondiente a la ocupación formativa, se caracteriza por conjuntos de estructuras aglomeradas y aisladas, edificadas mayoritariamente a partir de lajas verticales en hiladas simples, que forman un total de 153 recintos (Gutiérrez 2006 Ms). Las estructuras aglomeradas conforman un patrón recurrente consistente en la construcción de un recinto central circular, alrededor del cual se han adosado recintos menores, a los cuales se accede 
por vanos pequeños que se asemejan a los nichos registrados en el muro perimetral del templete de Tulan-54. En el costado exterior de uno de estos recintos en un depósito apegado a la estructura se obtuvo una datación radiocarbónica de 2780 AP, correspondiente al comienzo de ocupación.

Comparativamente con los asentamientos Tulan-54 y 85, este sitio, si bien es más extenso, presenta menos restos culturales. Los depósitos del exterior de los recintos, no alcanzaron a cubrir completamente las estructuras. Entre los materiales se registraron acumulaciones de restos vegetales, desechos de talla lítica en rocas silíceas, obsidiana y toba; cuentas, mineral de cobre, conchas, cerámica del tipo Los Morros, plumas, restos óseos, cordelería en fibra vegetal, fibras de origen animal, textiles en técnica de anillado, pigmento rojo y tendones.

Entre los artefactos líticos destacan instrumentos de uso cortante marginales y bifaciales, resultando particularmente interesante una lasca de filo vivo con restos de grasa en el borde activo, sugiriendo su uso en actividades de destazamiento, descuerado o esquila, además de una piedra plana de toba pintada con motivos lineales de color rojo. También se recuperaron microperforadores, láminas de toba con muescas pulidas, posiblemente utilizadas en la preparación de tientos y puntas pedunculadas de obsidiana. Entre los restos óseos de camélidos nuevamente aparecen ambos grupos de tamaño, además de un incisivo que por su morfología corresponde al grupo guanaco/llama. Entre la fauna menor, en un registro que es similar al de otros sitios ya referidos, se destaca la presencia de aves y roedores (Sigmodontinos, Ctenomys, Chinchilla lanigera y Lagidium viscacia).

\section{Tulan-54}

Este asentamiento se emplaza en el borde sur de la quebrada de Tulan, a unos $300 \mathrm{~m}$ al oeste del asentamiento Tulan-52. Hasta ahora se han identificado varios sectores que muestran una compleja organización del espacio, destacando un gran templete central (Núñez et al. 2005), otras estructuras de probable carácter habitacional a su alrededor, un cementerio hacia el borde sur (Tulan-58) y un bloque con grabado de felino en el norte, al borde de la quebrada (Figura 6).

Estructuras exteriores al templete. Con el fin de caracterizar los depósitos exteriores al núcleo ceremonial se excavaron 10 unidades de sondeo hacia los sectores norte (dos unidades), sur (tres unidades), este (dos unidades) y oeste (tres unidades), siguiendo ejes de coordenadas transversales. En todas las unidades excavadas se detectaron densos depósitos de basuras de hasta $1.80 \mathrm{~m}$; sin embargo, las unidades más alejadas no registraron

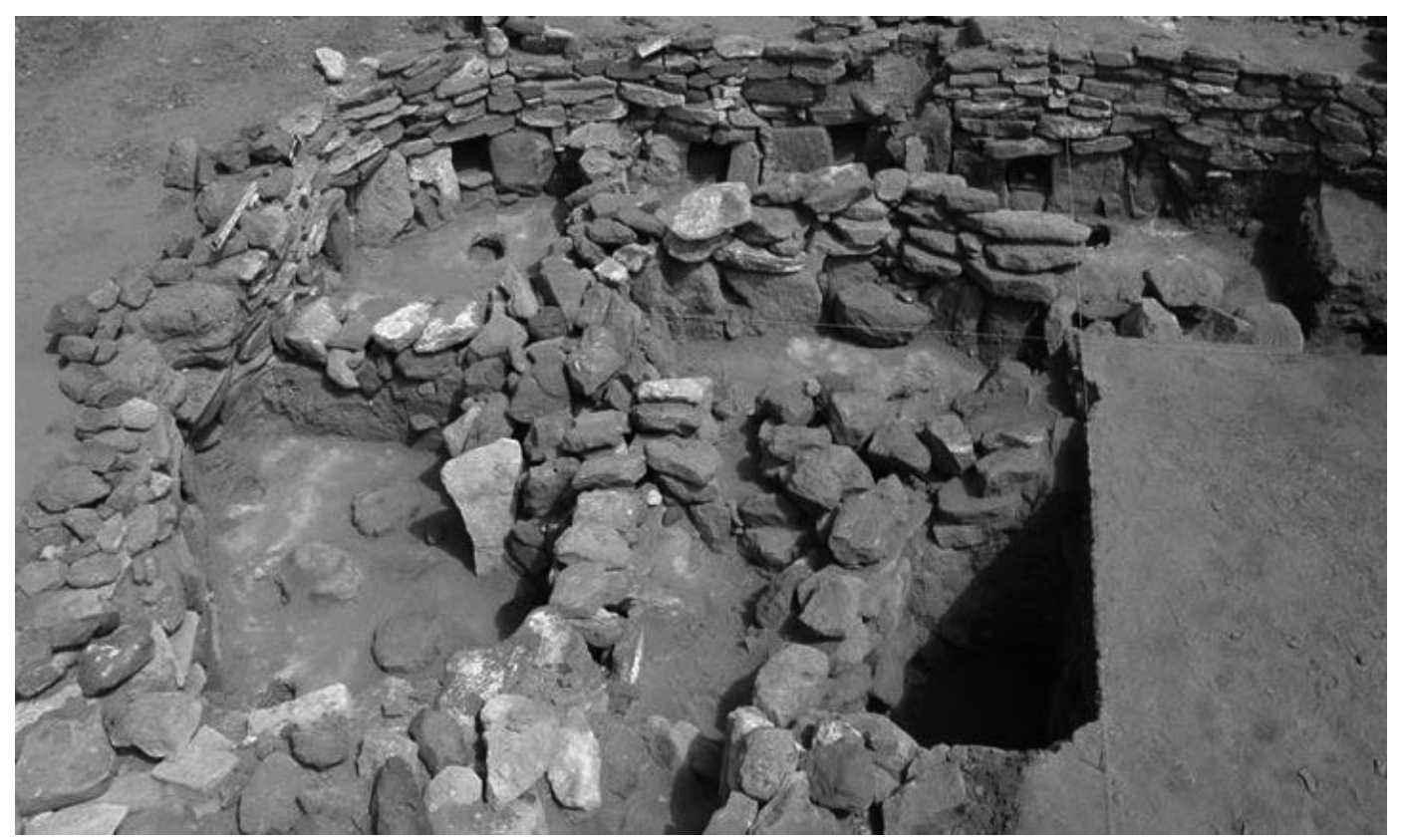

Figura 6. Vista general del templete en el centro de la aldea Tulan-54. 
depósitos tan profundos (entre $0.35 \mathrm{~m}$ y $0.60 \mathrm{~m}$ ), lo que permitió determinar que el sector donde se ubica el templete y aquel espacio aledaño a este, habría sido socavado al menos unos $0.70 \mathrm{~m}$. En todos los pozos de sondeo, menos en los ubicados en el sector este, se detectaron bloques de roca que fueron interpretados como partes de posibles estructuras habitacionales, las que se ubicarían alrededor de la estructura principal, situándose esta al centro del asentamiento. La ausencia de recintos en el sector este, es coincidente con la existencia de una rampa de acceso al templete.

Hacia el norte, en la unidad más cercana al núcleo ceremonial se identificó un bloque con un grabado de camélido, lo que motivó la extensión de las excavaciones en dicho sector. Esta ampliación permitió identificar muros curvos que se interpretaron como estructuras subcirculares construidas con grandes bloques verticales, sobre los que se disponen bloques de menor tamaño, con una técnica constructiva similar a la utilizada en el templete. Además, se detectaron al menos tres niveles constructivos: uno en la base o piso estéril a una profundidad de 1.80 $m$ de la superficie actual, otro en el sector medio del depósito y sobre basuras, a una profundidad de $0.80 \mathrm{~m}$, y otro a nivel de la superficie. Hacia el sector sur se detectaron bloques sobre basuras al fondo del depósito. De la unidad más cercana a la estructura principal se obtuvieron dataciones de 2990 y 2630 AP, lo que permite suponer que al menos en este sector las basuras comenzaron a depositarse antes que en el interior del templete, lo cual sugiere que las construcciones exteriores son anteriores al mismo. En los pozos excavados en el sector oeste, se registró una alta frecuencia de artefactos de molienda, fogones y bloques probablemente correspondientes a estructuras, a una profundidad aproximada de 1.50 $\mathrm{m}$, todo lo cual es indicador de intensas actividades domésticas.

Los depósitos fuera del núcleo ceremonial alcanzan hasta el $1.80 \mathrm{~m}$ y contienen restos de orden primario y secundario, con fogones y lentes extendidos de cenizas, abundantes restos vegetales, óseos y líticos. Entre los restos vegetales destaca la intensiva explotación de raíces comestibles de Scirpus y frutos de Opuntia. Además hay evidencia de consumo de ají (Capsicum) y quínoa (Chenopodium), obtenida del análisis de coprolitos (Holden 1991). Por otra parte, se observó una importante frecuencia de hilados en fibra animal, lo que contrasta con los escasos hilados en fibras vegetales registrados.
Llama también la atención la representación de algunos tejidos anillados y la ausencia de textiles planos (Dransart 1991). Por su parte, los restos óseos sugieren el consumo de camélidos adultos y subadultos, junto a roedores (Ctenomys y Lagidium viscacia) y aves en escasas cantidades (Labarca 2005). Entre los artefactos líticos, se observó una alta representación de microperforadores y cuchillos de uso expeditivo, además de raspadores, raederas, puntas pedunculadas, perforadores y manos de moler. Por último, los análisis de fanéreos en vellones e hilos han ratificado una significativa presencia de camélidos silvestres (vicuñas y guanacos), con baja representación de camélidos domésticos, principalmente llama, junto a una fibra de alpaca (Lama pacos) (Benavente 2005-6 Ms). Por su parte, los análisis osteométricos muestran la existencia de camélidos de tamaño grande (guanaco/llama) y pequeño (vicuña/alpaca).

El templete semisubterráneo de Tulan. Al centro del asentamiento Tulan 54, bajo las capas de un montículo estratificado, se localizó una estructura ovalada compuesta por un muro perimetral, reforzado desde el exterior con rocas irregulares y depósitos estratificados de descarte de actividades (Figura 6). Este fue construido con bloques verticales megalíticos incrustados en el piso estéril socavado y presenta 12 nichos rectangulares a nivel del piso, construidos con jambas y dinteles que, en ciertos casos, se encuentran intervenidos con petroglifos, consistentes en cabezas invertidas de camélidos, incisiones lineales y un pequeño camélido atado (Figura 7). Sobre esta hilada se dispusieron bloques acuñados más reducidos y horizontales, algunos semicanteados que en ciertos casos presentan pigmento rojo. Divisiones internas con muros más simples se orientan hacia una estructura central algo ovalada (F), constituyendo los recintos A, B, C, D, E y G, con acceso al exterior por un estrecho terraplén hacia el borde este (Figura 8). El templete presenta un piso nivelado de $85-90 \mathrm{~m}^{2}$, localizado entre 1.80 $1.90 \mathrm{~m}$ de la superficie del túmulo. En este piso se realizaron distintas actividades vinculadas con la inhumación de neonatos humanos, los que fueron dispuestos en pozos apegados al muro perimetral y también al interior de la estructura central.

Los neonatos que hasta ahora suman un total de 24 individuos dentro de un rango que privilegia edades hasta 12 meses (Costa $2005 \mathrm{Ms}$ ), se encuentran cubiertos con lozas y acompañados de distintas ofrendas, las que podrían manifestar cierta jerar- 


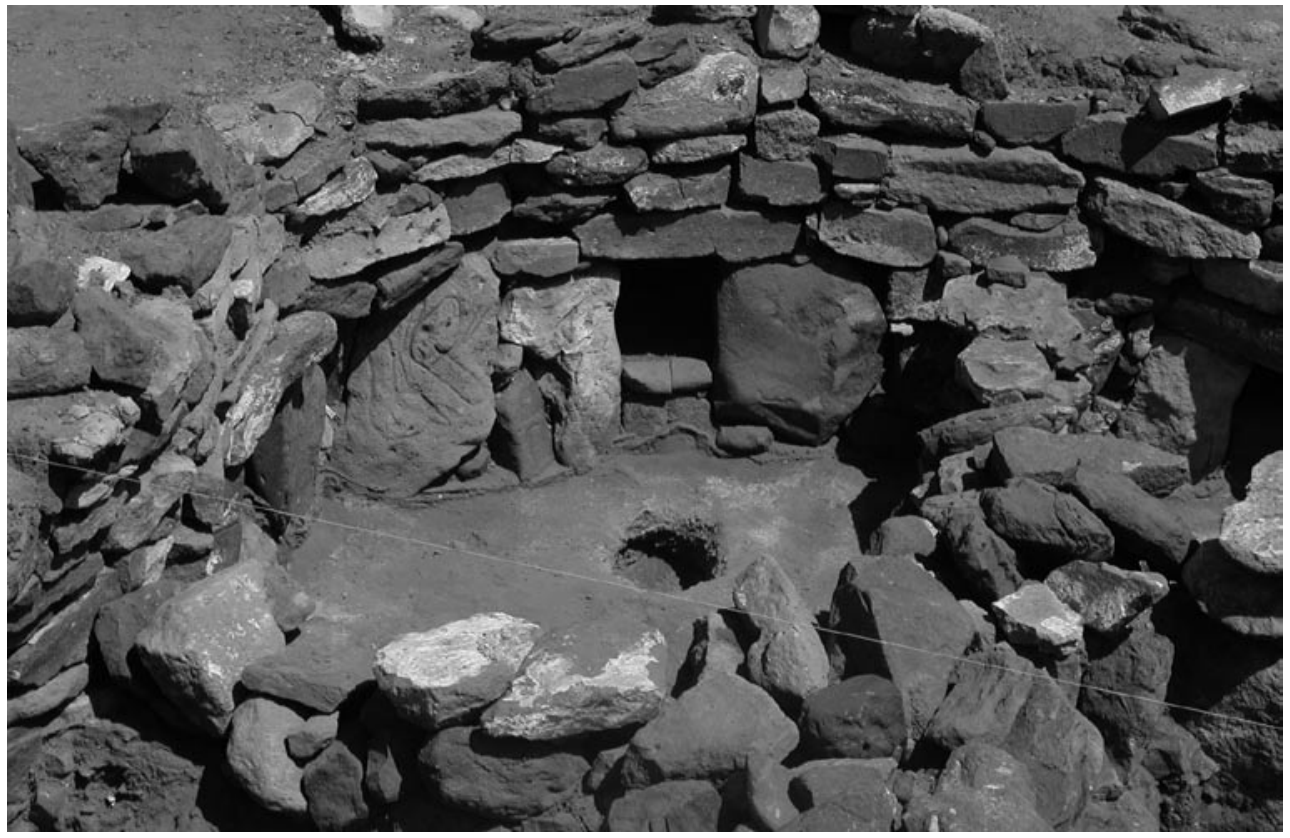

Figura 7. Muro perimetral con nicho y pozo de inhumación infantil del templete de Tulan-54.

quización. En efecto, dentro de estas se encuentran dos cubiletes líticos intencionalmente rotos con diseños de camélidos antropomorfizados. En uno de estos, los motivos representan camélidos alzados en cópula y, en el otro, de perfil, pintados de rojo y negro, con un personaje frontal en el centro (Figura 9). Otras ofrendas corresponden a colgantes de láminas de oro con rostros bivalentes humano $\mathrm{y}$ animal, con caras humanas opuestas repujadas y punteadas (Figura 10); una tapa de madera repujada en lámina de oro con diseño de cóndor (con cresta y ojos de crisocola), un gastrópodo de las yungas con pigmento rojo (Strophocheilus oblongus), cuentas confeccionadas con conchas del Pacífico y del oriente, así como con crisocola, brocantita, sulfuro y óxido de cobre, turquesa verde y dumortierita. Además, hay punzones óseos, una placa ovalada de plomo (Medina 2006 Ms), cestería en espiral; mineral de cobre triturado, conanas con uso inicial y en proceso de elaboración, fragmentos de cerámica retomada y una microescultura lítica de ave tropical (Núñez et al. 2006b).

Una muestra de carbón bajo el cráneo del individuo c23 fue datada en $2530 \mathrm{AP}$, mientras que de un fémur del individuo c10 se obtuvo una datación de 2550 AP. Por su parte, los dos neonatos del centro del templete, que se encuentran recubiertos con restos de un líquido lechoso y asociados a las dos láminas de oro y a uno de los cubiletes descrito, se fecharon indirectamente a partir de fogones ubicados sobre y bajo las inhumaciones, entre los 2490 y 2630 AP.

Estas inhumaciones se asocian con nichos y fogones circulares ubicados cerca de los enterratorios. Los fogones contenían restos de camélidos, aves y roedores, asociados a cuentas, microperforadores y mineral de cobre triturado. Las evidencias óseas fueron afectadas por eventos de combustión intensos, por lo que es posible interpretar estas evidencias con quemas, como ofrendas vinculadas a rogativas y ritos ejercidos in situ. Además, se identificaron tres pozos que sólo contenían ofrendas (sin inhumaciones) consistentes en grandes láminas de toba con escasas huellas de uso, punzones óseos completos, uno de los cuales posee un cabezal con hematita especular adherida con resina, un marán o gran machacador con impregnación de crisocola y un martillo con surco central.

Tomando en consideración el patrón etario de las inhumaciones, tal como lo sugiere la evidencia etnográfica y etnohistórica en otros lugares de los Andes, los infantes podrían ser considerados como intermediarios entre las rogativas y las deidades ancestrales, asociados a "mesas", festines y libaciones, en su calidad de seres reservados exclusivamente para el ceremonial (Eliade 1959; Burger y SalazarBurguer 1985; Rössing 1994; Brown 1995; Leonardi y Lau 2004). 


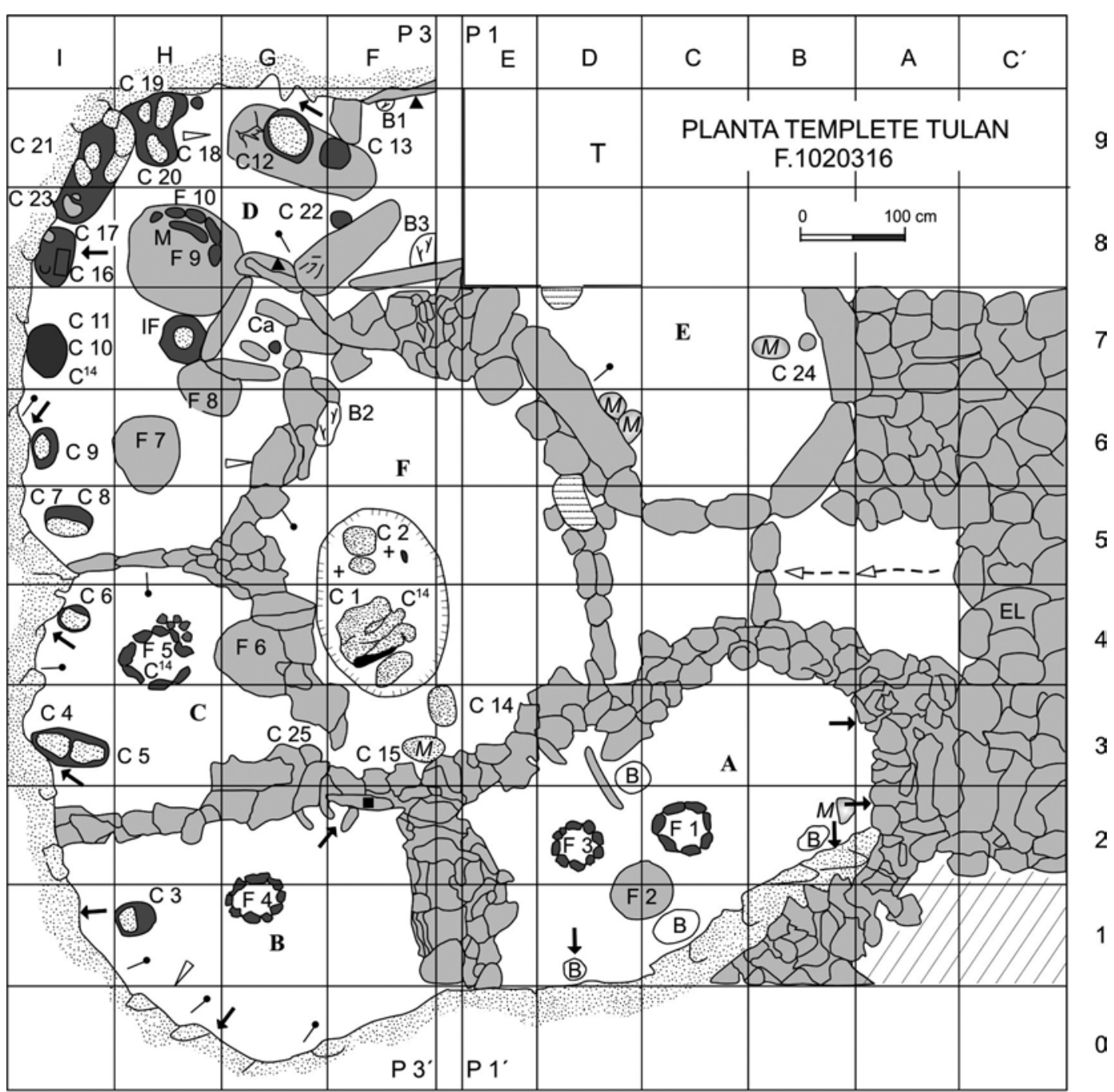

Le yenda

P1 - P1' / P3 - P3': Perfiles

$\mathrm{T}$ : Testigo

A, B, C, D, E, y F : Estructuras

$B$ : Bolsón socavado limpio

B1, B2, B3: Bolsón con ofrendas

F : Fogones estructurados y abiertos

C : Inhumaciones neonato en foso

IF : Inhumación falsa

$M$ : Mortero

\ : Tronco de cactus

- : Ofrenda de ave

: Muro perimetral $\square$ : Petroglifos en muros

- : Incisiones en muros

- : Ofrenda de maxilar de camélido

$\rightarrow$ : Nicho empotrado en muro perimetral

+ : Icono laminar de oro

im: Depresión central

$\checkmark-$ : Acceso inclinado

$\square$ : Placa petroglifo mueble

$\mathrm{Ca}$ : Estructura - caja

EL : Estructura lateral de apoyo al muro perimetral

$\square$ : Depósito de basura

ए1: Lapida sobre neonato en foso

Figura 8. Planta del templete de Tulan-54. 


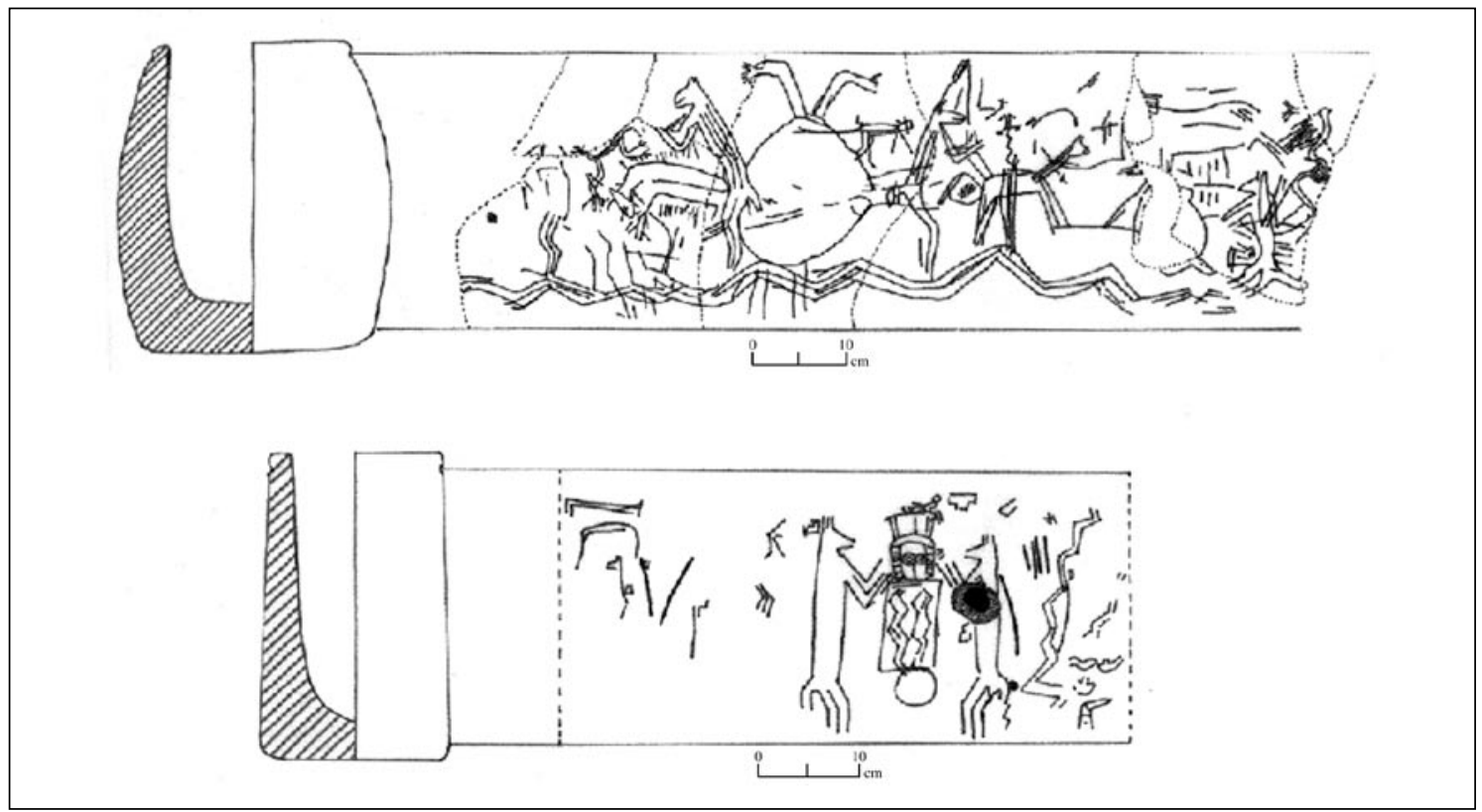

Figura 9. Cubiletes con grabados de camélidos antropomorfos ofrendados y "matados" en dos inhumaciones infantiles del templete.

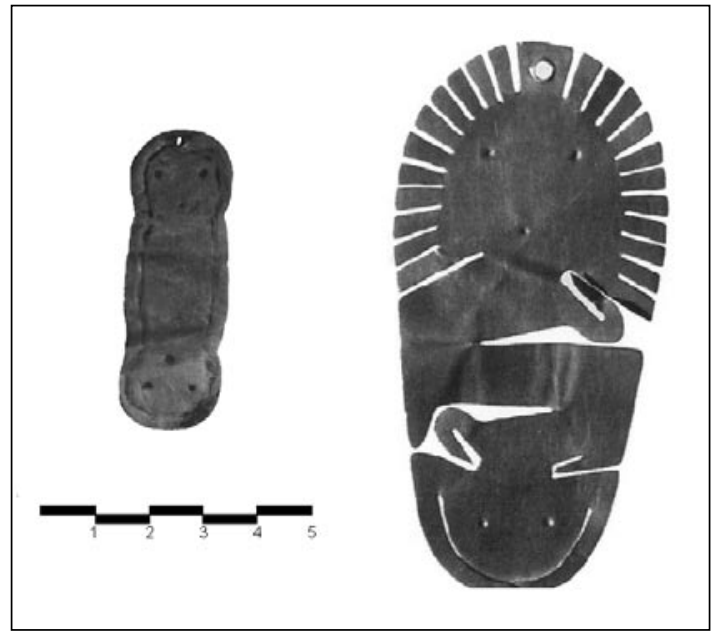

Figura 10. Colgantes de oro laminado y repujados de las ofrendas dispuestas en dos neonatos en el templete.

El piso original del templete no debió permanecer por mucho tiempo expuesto, dado que es probable que depósitos derivados de sucesivas actividades ceremoniales hayan comenzado a cubrir paulatinamente el interior de los recintos que componen esta estructura hasta colmatarlos. Esto habría generado un depósito estratificado principalmente de orden primario producto de actividades desarrolladas in situ, como lo sugieren los múltiples fogones y los patrones de descarte artefactuales y ecofactuales. Sin embargo, también es necesario considerar el aporte de desechos secundarios o la acumulación selectiva como lo sugiere la presencia de fragmentos cerámicos depositados intencionalmente (Uribe 2003 Ms; Kalazich 2006 Ms). Por otra parte, no se observan perturbaciones de los depósitos, así como tampoco reconstrucciones de estructuras ni extracción de materiales.

El descarte de restos en el interior del templete habría significado una filiación ritual y convergencia ceremonial, integrando el sentido de lo sacro con lo doméstico a través de un ocultamiento deliberado de los ritos fundacionales bajo la configuración de un montículo de basuras primarias (Eliade 1959; Bermann y Estévez 1995; Janusek 2004; Núñez et al. 2006b). En efecto, los depósitos intratemplete muestran una compleja materialidad que guarda relación con actos alimentarios y ritos muy particulares. Las personas faenan, comen y beben en torno a fogones, con artefactos adecuados para estos fines.

El análisis lítico (Estructura B-C), indica que los instrumentos formatizados más frecuentes son los microperforadores $(82 \%)$, seguidos de cuchillos formatizados o bifaciales y expeditivos, puntas de proyectil (principalmente pedunculadas), raspadores, láminas para preparar tientos, preformas y núcleos pequeños, relacionados con la extracción de matrices para microperforadores. Estos últimos se asocian a la confección de cuentas, especialmente en mineral 
de cobre, las que se registran en abundancia en los depósitos del sitio.

Algo más de 5000 fragmentos cerámicos han sido recuperados del total de las excavaciones en Tulan-54, los que constituyen un conjunto homogéneo de tipo monócromo, con superficies pulidas, craqueladas, engobadas y alisadas, con paredes y antiplástico grueso. Las superficies son de color negro, marrón, rojizo o gris. Los bordes son engrosados y redondeados, casi no se presentan asas, y las formas corresponden a vasijas subglobulares, vasos subcilíndricos, tiestos de bocas amplias usadas para cocinar (cuerpos tiznados) y otras más restringidas para beber. Se incluyen fragmentos retomados con huellas de pulido y abrasión e inclusive en forma de torteras. Esta alfarería presenta muy poca variación a lo largo de toda la secuencia estratigráfica, distinguiéndose ciertos rasgos estilísticos persistentes, como los rebordes engrosados en las bocas de vasijas no restringidas ("banda ancha") que se presenta en todo el depósito. La cerámica de la Fase Tilocalar se asemeja notablemente a aquellos tipos formativos tempranos identificados en el río Loa (Los Morros) y otros de las cuevas circumpuneñas trasandinas (García 1998; Sinclaire 2004; Uribe 2006). Por otra parte, algunos indicadores; como las pipas tubulares y angulares en cuerpos gruesos negros pulidos (Tarragó 1989), además de fragmentos corrugados y con impresiones de uña, permiten establecer conexiones con las tierras altas y bajas del Noroeste Argentino, particularmente con la tradición San Francisco y con componentes culturales como los de cueva de Cristóbal, datados a los 2860 AP (Fernández 1988-9).

Al interior del templete, los restos óseos de camélidos son muy abundantes, reconociéndose dos grupos de tamaños dentro de los cuales se advierten vicuña, alpaca y guanaco/llama. Asimismo, están presentes todos los rangos etarios, evidenciándose también patologías y deformaciones óseas diagnósticas (Cartajena et al. $2005 \mathrm{Ms}$ ). Dentro de los materiales confeccionados en restos óseos, destaca la producción de punzones, espátulas, retocadores, y otros instrumentos. Con respecto a la producción textil, la cordelería e hilandería se incrementa sensiblemente durante la Fase Tilocalar. Fuera de duda, la explotación de camélidos fue determinante en Tulan-54, tanto en su rol alimentario y artesanal, así como en sacrificios y festines rituales. Si se asume que los coprolitos de camélidos son un indicador de faenamiento in situ, es importante señalar que sólo en cuatro cuadrículas (I 8-9 / H 9-8) se contabilizó cerca de un millar de fecas, lo que sustenta la hipótesis de un origen primario de los depósitos al interior del templete.

En cuanto a los restos vegetales en los depósitos del interior del templete, se encuentran Scirpus, Opuntia, Atriplex, rica rica (Acantholippia riojana) y brea (Tessaria absinthiodes), además de una gramínea (Deyeuxia desertica Phil.) útil para la confección de cordelería. No se registraron evidencias de cultígenos, salvo unos pocos fragmentos de Lagenaria (Rodríguez 2005 Ms; McRostie 2006 Ms).

Resulta de particular interés el consumo de frutos de Opuntia cf atacamensis y de tubérculos de Schoenoplectus. Estos últimos pudieron ser utilizados como alimento, fibra y combustible, en tanto los frutos de Opuntia habrían sido sometidos a molienda para hacer más digestivo el consumo (Núñez y Hall 1982). Los frutos, semillas, tubérculos y raíces habrían requerido de prácticas de molienda, de modo que la presencia de manos y conanas es coherente con una importante alimentación subsidiaria. Sin embargo, debe recordarse que las evidencias de pigmento rojo (óxido de fierro) en algunos de estos instrumentos son una señal de que también fueron utilizados en funciones más específicas.

Cementerio Tulan-58. A unos $50 \mathrm{~m}$ al sureste del templete se identificó el extenso cementerio Tulan58 , cubierto superficialmente con rocas trasladadas (Cuadros 1 y 2). La excavación de prueba permitió segregar seis inhumaciones de adultos en posición horizontal decúbito dorsal con los pies algo flectados, de tradición arcaica, con ofrendas consistentes en microperforadores, cuentas, puntas pedunculadas y una mano con pigmento rojo. Asimismo, llama la atención otro adulto aledaño sentado, con un poste marcador de algarrobo, similar a aquellas inhumaciones formativas tardías del oasis de San Pedro de Atacama. Además, se registró un neonato con una microescultura lítica felínica dispuesta en la boca, acompañado por más de 400 cuentas. Esta coexistencia de dos tradiciones funerarias distintas, podría entenderse como la pervivencia transicional de un modo arcaico entre las prácticas formativas (Figura 11). El hecho de que existan neonatos en este cementerio indica que aquellos del templete eran efectivamente seleccionados para su inhumación al interior del templete. Una datación del orden de 2240 AP demuestra que los enterratorios localizados en la periferia tardía del cementerio 

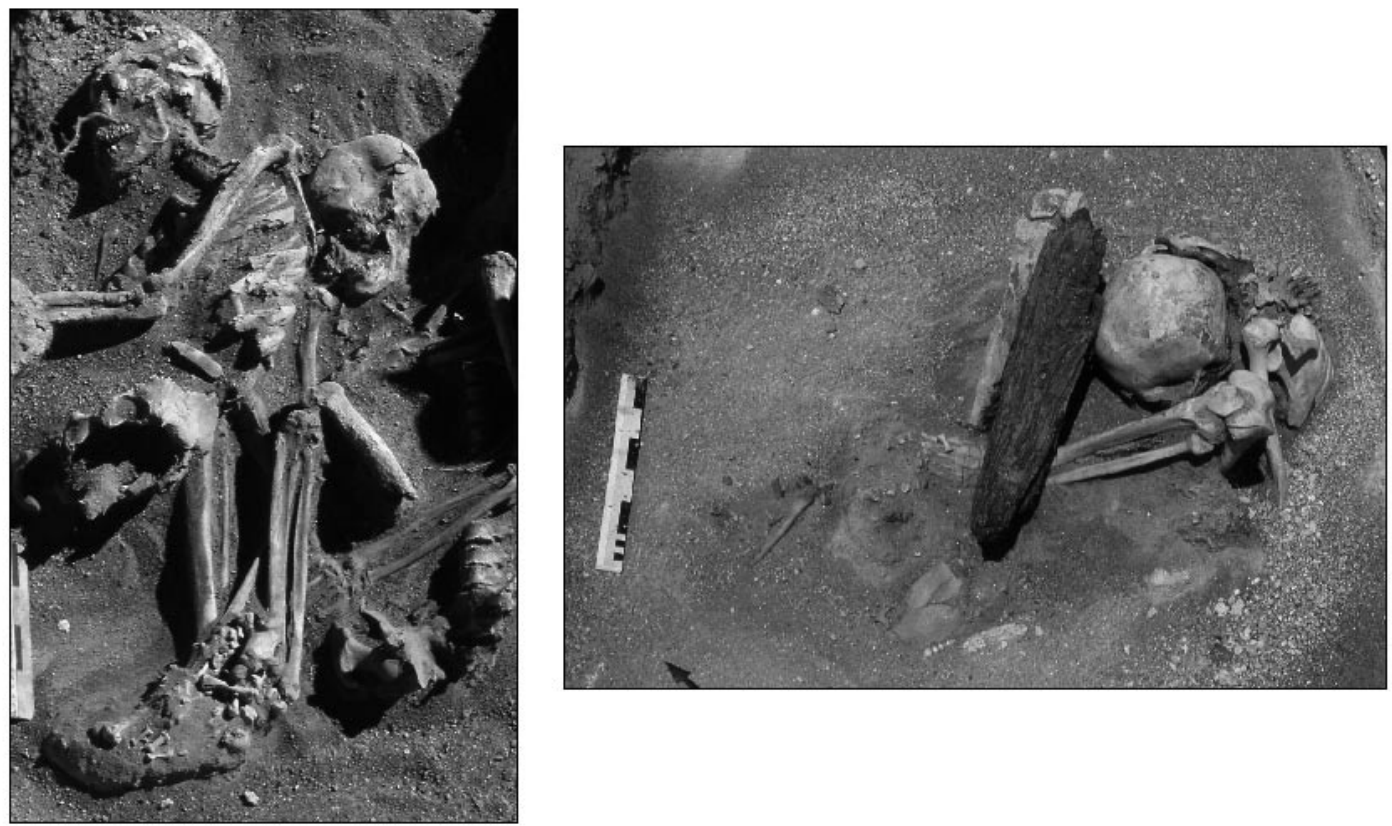

Figura 11. Inhumaciones de adultos en el cementerio Tulan-58. Izquierda: Inhumación decúbito lateral; Derecha: Inhumación de cuerpo flectado asociado a poste.

serían contemporáneas precisamente con el final de la Fase Tilocalar.

El registro cultural de la Fase Tilocalar, con sus variados tipos de sitios, permite postular ocupaciones diferenciadas en los distintos ámbitos y espacios de recursos del transecto Tulan, tanto bajo aleros como en grandes asentamientos abiertos. Las ocupaciones bajo abrigos rocosos, de carácter más transitorio, incluyen por un lado, énfasis en actividades rituales (Tulan-109) y, por otro, en labores temporales de carácter pecuario y doméstico (Tulan-55). Asimismo, los sitios abiertos incluyen tanto asentamientos de carácter habitacional (Tulan-122), como domésticos-rituales de gran envergadura, destacándose el templete de Tulan-54 y su aldea circundante. Asimismo, la complementariedad económica a lo largo del transecto se constata a través de ocupaciones que cubren todo el perfil desde la alta puna (Tulan99) ${ }^{8}$, hasta las vegas de Tilocalar localizadas en el Salar de Atacama (Tulan-85), si bien la mayor concentración se encuentra precisamente en la quebrada, en el tramo medio del transecto (sitios

8 Tulan-99: Campamento abierto de la Fase Tilocalar ubicado entre las lagunas Miscanti y Meniques.
Tulan-109, 55, 122, 54 y 58). Todavía falta más investigación para definir las relaciones funcionales precisas entre los sitios a lo largo del transecto, si bien la evidencia disponible parece favorecer la idea de que los sitios de mayor centralidad dentro del sistema de asentamiento se ubicaron cerca de los 3000 m.snm (Tulan-54).

\section{Análisis de materiales diagnósticos}

Los análisis de los artefactos y ecofactos considerados más sensibles para detectar continuidad y cambio han permitido precisar los contextos culturales y definir las orientaciones funcionales de los asentamientos que constituyen las tres fases de la secuencia Arcaico/Formativo en la quebrada de Tulan. En efecto, ha sido posible caracterizar e identificar las filiaciones de la alfarería formativa temprana de Tulan con los tipos definidos en el ámbito circumpuneño y sus zonas aledañas (Sinclaire $e t$ al. 1998; Uribe 2006; Kalasich 2006 Ms). De esta forma, ahora se sabe que la cerámica de la Fase Tilocalar es del mismo tipo que la descrita para la cuenca del Loa (Los Morros) (Uribe 2006; Kalazich 2006 Ms), además, la identificación de la cerámica Los Morros en el sureste del Salar de Atacama ha permitido ampliar su distribución bajo una dimensión más regional. Por otra parte, su identificación en los 
sitios de quebrada Tulan en secuencias estratigráficas datadas radiocarbónicamente nos ha permitido aportar una mayor precisión cronológica. Esto último incluye el registro de esta cerámica dentro de un marco temporal anterior a todo lo conocido, tal como se ha demostrado en los depósitos datados entre los 3400 y $3110 \mathrm{AP}$ en el asentamiento Tulan94 (Fase Tarajne). Sin embargo, esta cerámica no posee antecedentes en la localidad que permitan suponer una experimentación local, por lo que habría llegado tecnológicamente madura. Al respecto, la similitud de ciertos rasgos estilísticos y tecnológicos, tales como las superficies con impresiones de uña y corrugadas, y la presencia de pipas, permiten evidenciar conexiones con la vertiente oriental. Esta situación sugiere que el flujo de información trajo a la Puna de Atacama un conocimiento compartido y consolidado que marcó una notable innovación con respecto a la fase anterior (Uribe 2006; Kalazich 2006 Ms). Además, en particular las pipas podrían relacionarse con un hipotético tráfico temprano de cebil (Anadenanthera sp.) desde la vertiente oriental, donde se encuentran especímenes similares datadas por los 2600 AP (Dougherty 1972).

En relación a la naturaleza de los contenedores arcaicos, se ha constatado el uso de cestería en espiral desde el Arcaico Medio (Tulan-67), así como recipientes líticos y de calabazas (Lagenaria sp.) durante el Arcaico Tardío (Tulan-52). La utilización de estos recipientes se mantuvo en la Fase Tilocalar, aunque limitando en alguna medida sus contextos de uso al ámbito ritual (uso de cubiletes líticos y cestería en inhumaciones de neonatos en Tulan-54). En el contexto doméstico, la cerámica efectivamente se introduce desde la Fase Tarajne, reemplazando paulatinamente a los antiguos contenedores, hasta transformarse en una de las producciones más importantes de la Fase Tilocalar.

La amplia disponibilidad de recursos líticos como las grandes canteras de toba en el sector norte de la quebrada (Tulan Cerros), las fuentes de rocas silíceas hacia el borde sur y de obsidiana en la alta puna (Escola et al. $2005 \mathrm{Ms}$ ) han favorecido una intensa y eficiente producción de artefactos líticos. Al respecto, se ha podido precisar el cambio desde una industria orientada principalmente a la caza durante el Arcaico Tardío, manifestada en el predominio de puntas de proyectil foliáceas e instrumentos para actividades de faenamiento, a otra más fuertemente orientada a la elaboración de microperforadores para la confección de cuentas. En relación a estas últimas, cabe señalar que, si bien existe una importante producción de cuentas durante el Arcaico Tardío, es en la Fase Tilocalar donde esta se hace más intensiva. Por otra parte, en las fases Puripica-Tulan y Tarajne las cuentas se confeccionaban preferentemente en conchas del Pacífico, en tanto que durante el Formativo Temprano se opta por un mayor uso del mineral de cobre de origen local (Soto $2006 \mathrm{Ms}$ ). Estas cuentas de la Fase Tilocalar se asociarían a una sobreproducción local dentro de probables redes tempranas de circulación macrorregional ${ }^{9}$ (Rees 1999; Ventura 1999; Rees y de Souza 2004; Núñez et al. 2006 Ms-a). Dentro de esta circulación de bienes, caben destacar los hallazgos en Tulan-54 de obsidiana trasladada desde las cercanías de San Antonio de los Cobres, en la puna trasandina, de acuerdo a lo indicado por los análisis físico-químicos (Escola et al. $2005 \mathrm{Ms}$ ).

En cuanto al material malacológico, se advierte que durante al Arcaico Tardío se encuentran sólo especies del Pacífico (Oliva peruviana, Pecten purpuratus), a las que en la Fase Tilocalar se suman conchas trasladadas desde la vertiente oriental (Strophocheilus oblongus). Esto permite afirmar que durante el Formativo Temprano se amplían notablemente las redes de circulación de estos bienes, lo que está en coherencia con los indicadores de circulación regional mencionados a partir de las otras materialidades.

Por otra parte, las prácticas de molienda son importantes en toda la secuencia descrita; no obstante, se produce un cambio morfológico en los molinos, registrándose en el Arcaico Tardío morteros de hueco cónico, mientras que en el Formativo Temprano son frecuentes las conanas. Dentro de la industria de piedra pulida, cabe señalar la presencia de artefactos cilíndricos en el sitio Tulan-52, los cuales conformarían los antecedentes tecnológicos de los cubiletes grabados e identificados entre las ofrendas al interior del templete de Tulan-54. Al respecto, otra tecnología lítica específica que se observa desde el Arcaico al Formativo es la industria de láminas,

\footnotetext{
9 Hasta ahora no existen análisis físico-químicos que permitan demostrar el movimiento de las cuentas cupríferas confeccionadas en Tulan a nivel macrorregional. Sin embargo, la proporción entre cuentas y microperforadores en los sitios de la Fase Tilocalar favorece ampliamente a estos últimos (lo que no ocurre en los sitios arcaicos, como Tulan-52), lo que sugiere una producción de cuentas cuyo consumo excede los requerimientos locales (Núñez et al. 2006 Ms-b)
} 
las que son utilizadas principalmente en forma expeditiva para labores que requieren de bordes con filos extendidos, aunque durante el Formativo se agregan funciones para este tipo de matrices, como la posible preparación de tientos mediante muescas pulidas.

Otra manifestación cultural importante es el arte rupestre, identificado al interior de los sitios habitacionales y en distintos sectores de la quebrada. Se ha notado que elementos tales como las incisiones lineales, identificadas inicialmente en el campamento arcaico tardío Puripica-1 y algunos rasgos característicos del estilo Kalina, se observan desde el Arcaico Tardío al Formativo Temprano (Nuñez et al. 2006a). Por su parte, la alta presencia de paneles del estilo Taira-Tulan asociados a asentamientos del Formativo Temprano, sugiere una relación con el creciente desarrollo aldeano y las prácticas pastoralistas (Berenguer 1995, 1996; Gallardo 2001). Asimismo, los grabados en distintos sitios, tanto en aleros como al interior de asentamientos con arquitectura, sugieren el desarrollo de actividades ceremoniales en dos clases de espacios restringidos, tal como se observa en Tulan-109 y 54, donde se han constatado los estilos Taira-Tulan y Confluencia, respectivamente. Esto último destaca la diversidad de patrones de arte rupestre propios del Formativo Temprano, ratificando la contemporaneidad propuesta para ambos patrones estilísticos (Gallardo y Yacobaccio 2005).

Los análisis arqueofaunísticos aplicados a restos de camélidos permitieron identificar durante el Arcaico Tardío dos grupos de tamaño: uno pequeño (vicuña) y otro grande (guanaco/llama). Este último presenta una gran variabilidad métrica, lo que indicaría la presencia de los primeros animales domésticos (Cartajena et al. 2003 Ms, 2005 Ms). Sin embargo, los fanéreos identificados durante la Fase PuripicaTulan corresponden mayoritariamente a animales silvestres con un predominio de vicuña, seguido por guanaco, y una menor frecuencia de fanéreos de llamas (Benavente 2005-6 Ms). Es importante indicar la existencia de patologías (exostósis) y deformaciones, especialmente a nivel de las extremidades inferiores, lo que reflejaría la manipulación humana, ya sea a través de restricciones alimenticias o, con mayor probabilidad, de funciones de carga.

Durante la Fase Tilocalar continúan observándose dos grupos de tamaño en los camélidos, no obstante, aquel de tamaño grande tiene una menor dispersión, lo que podría deberse a la maduración del proceso de domesticación, como también a la selección de un grupo más homogéneo para actividades domésticorituales propias del templete Tulan-54. Esta selección también se distingue a través del perfil etario y de las unidades anatómicas, las cuales difieren de aquellas observadas en las unidades extratemplete. En el grupo de animales pequeños se identificaron numerosos restos de vicuñas; no obstante, se detectaron algunos incisivos característicos de alpaca (Cartajena et al. 2003 Ms, 2005 Ms). En relación a esto, los fanéreos permitieron determinar nuevamente, la existencia mayoritaria de fibras y vellones de vicuña, seguida por guanaco y en menor proporción de llama, junto a una fibra de alpaca (Benavente 2005-6 Ms). En este sentido, la caza de animales silvestres mantiene su importancia durante el Formativo, no sólo para la obtención de carne y materias primas, sino también en el ámbito simbólico como lo denota el hallazgo de estólicas en el sitio Tulan-109, así como un gancho fracturado en el nivel temprano del templete, y de un grabado del estilo Confluencia representando la cacería con dardos. ${ }^{10}$ Sin embargo, a pesar de las evidencias de propulsores y dardos, esta pervivencia de las actividades de caza se habría sustentado por la introducción del sistema arco-flecha (de Souza 2006), permitiendo así satisfacer las demandas de productos de origen animal sin necesidad de sacrificar mayormente el ganado doméstico. De acuerdo a lo anterior, es importante señalar que la llama presentaría una fuerte orientación a las funciones de carga como lo denota la detección de patologías y deformaciones, acorde con las evidencias de bienes insertos en una red de intercambio extrarregional (Benavente 1984, 2005-6 Ms; Cartajena 1994; Cartajena et al. 2003 Ms, 2005 Ms).

Los análisis arqueobotánicos han permitido verificar la insuficiente importancia de las plantas cultivadas dentro del proceso arcaico/formativo en la quebrada de Tulan. En efecto, todos los análisis de micro y macrorrestos han permitido identificar escasos cultígenos correspondientes a Lagenaria, Capsicum, Chenopodium y Zea mays (Holden 1991; Bueno 2004 Ms; McRostie 2006 Ms). Con respecto a la baja presencia de frutos de especies arbóreas silvestres, como chañar (Geoffrea decorticans) y

10 Hay que destacar el hecho de que se trata del primer motivo atribuible a este estilo localizado al interior del templete que se encuentra realizado por técnica de grabado, a diferencia de lo que ocurre en otras partes de la Puna de Atacama, donde sólo se han identificado pinturas (Gallardo et al. 1999; Gallardo y Yacobaccio 2005) 
algarrobo (Prosopis sp), es posible que estos fueran procesados en forma primaria por grupos de tareas radicados temporalmente en el oasis de Tilomonte, trasladándose sólo las harinas hacia los asentamientos de la quebrada. Algo similar podría pensarse en relación a los cultígenos, considerando la escasez detectada. De ser así, las prospecciones en el oasis de Tilomonte, al no dar cuenta de grandes asentamientos como los identificados en los ambientes de pastoreo y caza localizados en la quebrada, confirmarían su carácter de espacio complementario, pero no decisivo para la subsistencia de las poblaciones formativas tempranas asentadas en quebrada Tulan. Por otra parte, la representación de plantas forrajeras que actualmente sólo son comunes en el piso altoandino (Scirpus sp.) podría ser explicada por una movilidad hacia los pisos más altos, si bien no hay que descartar la posibilidad de que el piso de forraje altoandino, a raíz de la recuperación húmeda desde los 3000 AP, haya bajado hasta las cotas de quebrada Tulan y su entorno (Grosjean et al. 1996).

El ambiente del transecto Tulan pudo dar lugar a prácticas hortícolas de baja escala, acorde al registro arqueológico, optándose por los espacios del desagüe del arroyo en el ámbito de los oasis piemontanos más cercanos localizados en Peine y Tilomonte. Sin embargo, la superficie se encuentra altamente erosionada, lo que no ha permitido hasta ahora identificar yacimientos de la Fase Tilocalar con el fin de contrastar esta hipótesis. Hasta el momento, se han identificado marlos de maíz (Zea mays) y restos de cucurbitáceas in situ, en el perfil estratigráfico del asentamiento Tulan-85, asociados a carbones datados en 2660 AP (Núñez 1999). Además, en el estrato inferior de la cueva Tulan-55 se fecharon cucurbitáceas y granos de maíz junto a hojas en 3010 AP. Mientras que de coprolitos humanos y contenidos intestinales procedentes de un depósito de basuras extratemplete, y de cuerpos inhumados en el cementerio Tulan-58, se identificaron restos de ají (Capsicum sp.), quinoa (Chenopodium sp.) y calabazas (Lagenaria), evidencias que cubren un rango cronológico entre los 3080 a 2240 AP (Holden 1991; Núñez 1999).

\section{Conclusiones}

El estudio de sociedades cazadoras recolectoras que transitaron hacia el sedentarismo y la producción de alimentos ha sido un tema ampliamente tratado en la literatura, generalmente enfocado desde una perspectiva agrocentrista enfatizando el rol de la agri- cultura (Arnold 1996a), o bien, con un fuerte énfasis en términos de una secuencia de estados progresivos de desarrollo entre la caza recolección y el pastoralismo (Layton et al. 1991). Sin embargo, durante las últimas décadas se ha prestado especial interés a las sociedades cazadoras recolectoras complejas (Price y Brown 1985; Arnold 1996b, entre otros) y el paso hacia sociedades pastoralistas neolíticas (Peters et al. 1999; Aurenche y Koslowski 2003, entre otros). Desde la percepción regional de los Andes, el proceso de "neolitización“ andina (Lavallée 1989) llamó la atención sobre la estrecha relación entre la caza y el surgimiento del pastoralismo, donde el aporte de los cazadores recolectores altoandinos en agregaciones semisedentarias y sedentarias, y la explotación de camélidos en escalas espaciales discretas, habrían conducido a prácticas de cacerías especializadas y pastoralismo (Wheeler et al. 1977; Rick 1983). El tránsito caza-domesticación de camélidos condujo a un incremento gradual de las labores de crianza, de modo que durante el Formativo Temprano se ha aceptado ampliamente el manejo ganadero (Núnez 1981; Benavente 1984; Cartajena 1994; Yacobaccio et al. 1994; Olivera 1998; Yacobaccio 2001, entre otros) con un importante aporte de la caza de camélidos silvestres (Wheler et al. 1977; Yacobaccio y Madero 1988 Ms; Yacobaccio et al. 1994; Cartajena 1994; Cartajena et al. 2005 Ms), situación bivalente también reflejada en el arte rupestre en donde escenas de cacerías (estilo Confluencia) son contemporáneas con el estilo Taira-Tulan correspondiente a camélidos domésticos (Gallardo y Yacobaccio 2005). En este sentido, la extensión de altiplanicies en los áridos ambientes del Altiplano Meridional y Circumpuna habría valorado el desarrollo del pastoralismo por sobre los logros agrarios, tal como se ha advertido entre diversas comunidades formativas como Wankarani (McAndrews 2005) y en nuestro caso concreto, aquellas asentadas en la vertiente occidental de la Puna de Atacama.

Es precisamente, en torno al desarrollo de los "cazadores recolectores complejos" (Arnold 1996a y 1996b) en donde observamos los gérmenes de las transformaciones formativas. Desde estos antecedentes hay consenso en el centro-sur andino que las prácticas pastoralistas no significaron el colapso de las sociedades cazadoras recolectoras, sino el desarrollo de un proceso de integración paulatina bajo estrategias productivas innovadoras (Yacobaccio et al. 1994; Goñi y Olivera 1996; Núñez 2005). La valoración regional del rol de las agrupaciones de cazadores domesticadores que optan por espacios 
con alta circunscripción social, movilidad reducida a prácticas trashumantes e intensificación de explotación de recursos permitió crear las condiciones para el tránsito en los mismos territorios hacia la emergencia de complejidad social y ritual (Yacobaccio 2001; Núñez et al. 2006b).

En este contexto a través de una propuesta de investigación multidisciplinaria se ha identificado la trayectoria de un proceso sociocultural desde el Arcaico Tardío al Formativo Temprano en la quebrada de Tulan, que ha permitido caracterizar y definir su naturaleza transicional en un marco de complejidad social más temprano de lo esperado (Figura 12). Lo anterior permite postular un desarrollo creciente, de escala espacial discreta, donde la combinación de los factores sociales, rituales, productivos y ambientales, dieron origen a sociedades formativas singulares en la Subárea Circumpuneña. De esta forma, se aporta a una mejor comprensión de la diversidad de las sociedades formativas tempranas situadas en el extremo meridional de los Andes Centro-Sur.

Efectivamente, se han identificado indicadores culturales que dan cuenta de la transición arcaica desde la Fase Puripica/Tulan (4580-3860 AP) hacia las fases Tarajne (3640-3110 AP) y Tilocalar (3130-2380 AP), correspondientes a patrones arquitectónicos, conjuntos artefactuales y arte rupestre, entre otros. Si bien las ocupaciones arcaicas tardías se encontraban insertas en un medio ambiente más árido, la recuperación de las condiciones húmedas, sincrónica con la ocupación de Tulan-54 (Grosjean et al. 1996; Latorre et al. 2002), habría favorecido el desarrollo pastoralista en un escenario propicio, con un sedentarismo plenamente dinámico (sensu

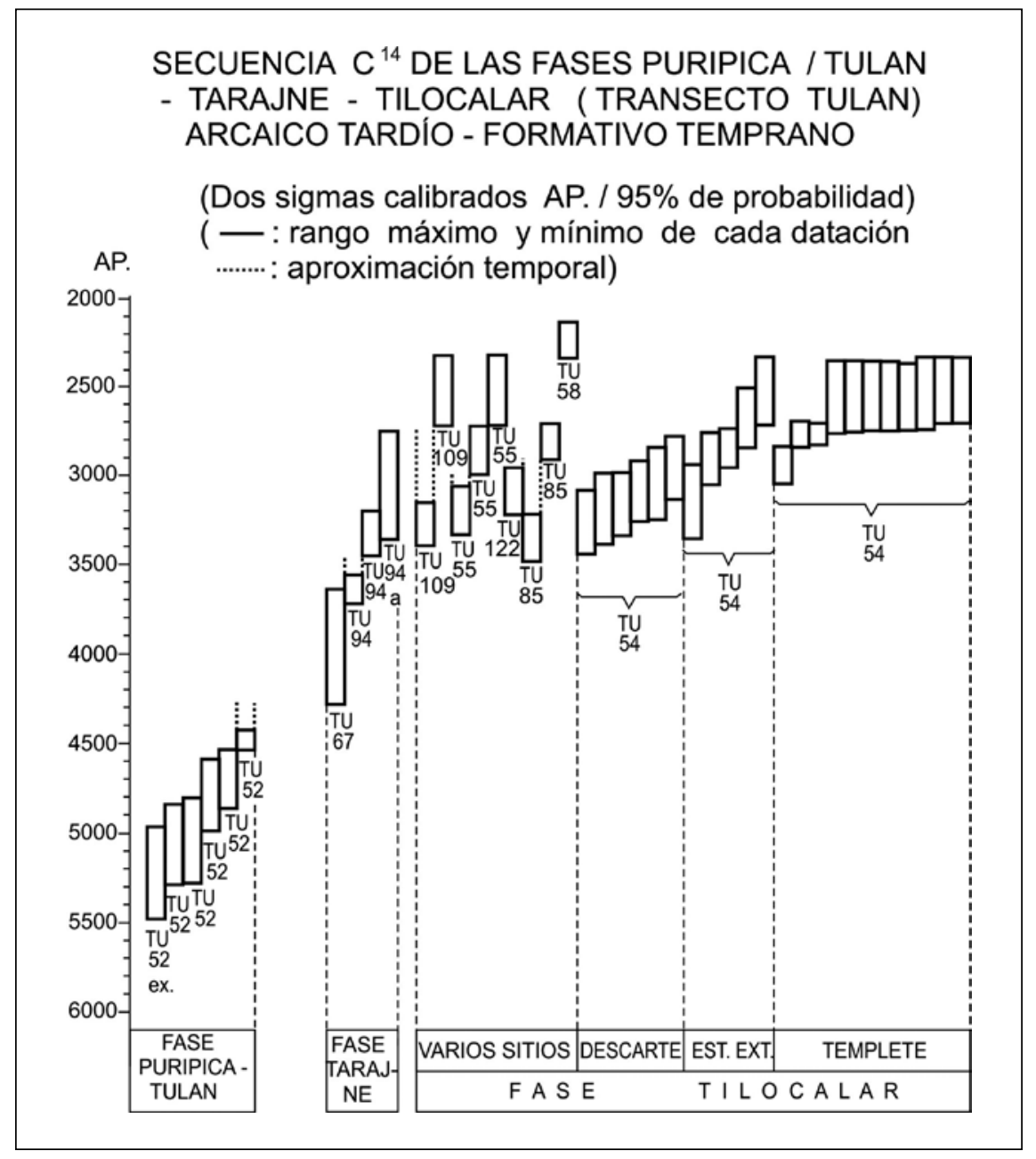

Figura 12. Secuencia de fechados radiocarbónicos de las fases Puripica-Tulan, Tarajne y Tilocalar. 
Olivera 2000). Este escenario espacialmente acotado habría favorecido la circunscripción social con un considerable incremento de aglomeración residencial, reducción de movilidad y especialización en crianza de camélidos, junto a cacería intensiva, complementada por prácticas hortícolas, de recolección y labores minero-metalúrgicas. A lo anterior se puede agregar una importante circulación de bienes de estatus insertos en tempranas redes de interacción caravanera macrorregional entre costa y selva (Núñez et al. 2006 Ms-a).

La quebrada de Tulan, con una extensión de 30 $\mathrm{km}$ entre las tierras altas y el borde del Salar de Atacama, concentra recursos de agua subterránea y superficial, forraje estable, canteras y pisos ecológicos complementarios, favorables para el desarrollo de asentamientos estables y circunscritos. En este medio, y luego de una prolongada ocupación, los grupos alcanzaron formas de organización sociocultural suficientes para permitir el desarrollo de una mayor complejidad social. De este modo, tales recursos fueron manejados por pequeñas agrupaciones eficientes orientadas a la producción de alimentos y bienes, alcanzando un desarrollo aldeano bajo un nuevo contexto ideológico. Este último se manifiesta en el surgimiento de arquitectura ceremonial y monumental, grandes paneles con arte rupestre, ritos fundacionales funerarios de neonatos y ofrendas. Tales manifestaciones denotan cierta jerarquización social donde una élite emergente busca establecer un nuevo orden social, político, económico y simbólico.

Esta complejidad creciente se asemeja a las manifestaciones culturales de los Andes Centro Sur propias del Formativo Temprano, tales como Chiripa y Wankarani, en donde se registran templetes colmatados de basuras, inhumaciones infantiles, ofrendas y ritos asociados (Bermann y Estevez 1995; Beck 2004). No obstante, en el caso de quebrada Tulan se presentan particularidades de menor escala como su arquitectura monumental especialmente diseñada para inhumaciones de neonatos, profusas y variadas expresiones en arte rupestre y una intensa producción de cuentas de mineral de cobre, que la singularizan en el ámbito circumpuneño.

En el norte de Chile no se han registrado hasta ahora asentamientos complejos de esta naturaleza fuera del sureste del Salar de Atacama; sin embargo, se han identificado ocupaciones sincrónicas con indicadores propios de la Fase Tilocalar en el río Loa, en la cuenca del río Vilama y en los oasis de San Pedro de Atacama (Benavente 1984; Aldunate et al. 1986; Sinclaire 2004; Thomas et al. 2002; Agüero 2005). Estos indicadores también se han registrado en la vertiente oriental de la puna y yungas aledañas (Raffino 1977; Fernández 1988-9; Aschero et al. 1991 Ms; García 1998; Ventura 1999), lo que ratifica la existencia de rutas de interacción tempranas de larga distancia (Nielsen 2006) e invita a ampliar estas investigaciones en una escala mayor.

Durante un período comprendido entre los 3200 a $2300 \mathrm{AP}$, mientras las sociedades del centro sur andino adoptaban diversas modalidades de vida, acordes con la domesticación de sus respectivos paisajes culturales, la Fase Tilocalar representaría los inicios de la tradición pastoralista con suficiente autonomía y particularidades propias de la Circumpuna. Puesto que no existe un modelo único que caracterice a las sociedades ganaderas, el pastoralismo de la Fase Tilocalar se manifiesta en el desarrollo de actividades productivas y rituales relacionadas con la crianza de camélidos domésticos, pero a la vez intensificando la caza y la producción de bienes excedentarios, e integrando otros sectores productivos tales como minería, metalurgia, recolección y horticultura. Este contexto habría determinado el crecimiento de una sociedad compleja con antecedentes enraizados en el Arcaico Tardío, dando lugar a su vez a los desarrollos socioculturales posteriores.

El pastoralismo es aceptado como un intento holístico por integrar no sólo el componente doméstico, sino un conjunto de evidencias socioeconómicas y culturales que permiten sustentar una transformación sustancial en las relaciones sociales (Ingold 1980). Las investigaciones orientadas a comprender la consolidación del modo de vida formativo abren por ahora una ventana para captar lo sucedido entre los 4500 a 2400 AP en el ámbito circumpuneño y, por lo mismo, nos acercan a la comprensión de una de las transformaciones socioculturales más trascendentales ocurridas en los Andes.

Agradecimientos Los autores agradecen a los miembros de la comunidad indígena de Peine: Ramón Torres, Oriana Mora, Fernando Varas, Tatiana Chaile, Orlando Torres, Eli Toroco, María Cruz, Sonia Cruz, Ana Yapura, Marco Barrera, Néstor Morales, Miguel Paz y Leydi Barrera. A los investigadores Betty Meggers, Fernanda Rodríguez, Tim Holden, Virginia Popper, Luis F. Ferreira, Carlos Aschero, M. Antonietta Costa, 
Penny Dransart, Hugo Yacobaccio, Salomón Hocsman, Pilar Babot, Vivien Standen, Antonia Benavente, Lidia García y Mario Pereira, por sus importantes aportes. A los tesistas, practicantes y colaboradores del Departamento de Antropología de la Universidad de Chile: Ricardo Paredes, Rafael Labarca, Virginia McRostie, Felipe Gutiérrez, Fernanda Kalazich, Liliana Bueno, Ignacio Torres, Francisco Rivera, Catalina Soto, Mariana Ugarte, Andrea González, Elisa Calas,
Boris Santander, Carlos Uribe, Francisco Bahamondes y Daniel Pascual. Asimismo, al personal del Museo de San Pedro de Atacama: Santiago Ramos, Timoteo Cruz, Luis Ramírez y Tomás Cruz. A los asistentes del proyecto: Lidia Ramos, Tommy Cruz, Jimena Cruz, Naotochi Itichi y Wilfredo Faúndez. A FONDECYT, por apoyar esta línea de investigación con el respaldo de la Universidad Católica del Norte, Universidad de Chile y Universidad de Berna.

\section{REFERENCIAS CITADAS}

AGÜERO, C., 1994. Madejas, hilados y pelos: Los turbantes del Formativo Temprano en Arica, norte de Chile. Tesis para obtener el Título de Arqueóloga. Departamento de Antropología, Universidad de Chile, Santiago.

2005. Aproximación al asentamiento humano temprano en los oasis de San Pedro de Atacama. Estudios Atacameños 30: $29-60$

AGUERRE, A., A. FERNANDEZ DISTEL y C. ASCHERO, 1973. Hallazgo de un sitio acerámico en la quebrada de Inca Cueva (Provincia de Jujuy). Relaciones de la Sociedad Argentina de Antropología 7: 197-214.

ALDUNATE, C., J. BERENGUER, V. CASTRO, L. CORNEJO, J. L. MARTINEZ y C. SINCLAIRE, 1986. Cronología y asentamiento en la región del Loa Superior. Dirección de Investigaciones y Biblioteca, Universidad de Chile, Santiago.

ARNOLD, J. E., 1996a. Organizational transformations: Power and labor transformations among complex gatherers and other intermediate societies. En Emergent complexity: The evolution of intermediate societies, J. E. Arnold (Ed.), pp. 59-73. Michigan International, Ann Arbor.

1996b. The archaeology of complex hunter-gatherers. Journal of Archaeological Method and Theory, 3: 77-126.

ASCHERO, C., 1994. Reflexiones desde el Arcaico Tardío (6000-3000 AP). Rumitacana 1: 13-17.

ASCHERO, C., M. PODESTA y L. GARCIA, 1991 Ms. Pinturas rupestres y asentamientos cerámicos tempranos en la Puna argentina.

AURENCHE, S. y S. K. KOZLOWSKI, 2003. El origen del Neolítico en el Próximo Oriente: El paraíso perdido. Ariel Prehistoria, Barcelona.

BECK JR., R. A., 2004. Architecture and polity in the formative Lake Titicaca Basin, Bolivia. Latin American Antiquity 15 (3): 323-343.

BENAVENTE, A., 1984. Chiu-Chiu 200: Una comunidad de pastores tempranos en la Provincia del Loa (II Región). En Actas del IX Congreso Nacional de Arqueología Chilena, pp. 75-94. La Serena.
2005-6 Ms. Análisis lanimétrico de fanéreos de los sitios Tulan-52 y 54. Informe de Avance, Proyecto FONDECYT 1020316.

BERENGUER, J., 1995. El arte rupestre de Taira dentro de los problemas de la arqueología atacameña. Chungara 27 (1): 7-43.

1996. Identificación de camélidos en al arte rupestre de Taira: Animales silvestres o domésticos? Chungara 28 (1-2): $85-114$

2004. Cinco milenios de arte rupestre en los Andes atacameños: Imágenes para lo humano, imágenes para lo divino. Boletín del Museo Chileno de Arte Precolombino 9: $75-108$

BERENGUER, J. e I. CACERES, 1989. Correlaciones entre arte rupestre y asentamientos de pastores en el Alto Loa. Boletín del SIARB 3: 57-60.

BERMANN, M. y J. ESTEVEZ, 1995. Domestic artefact assemblages and ritual activities in the Bolivian Formative. Journal of Field Archaeology 22 (3): 389-398.

BINFORD, L., 1988. En busca del pasado. Crítica, Barcelona.

BONNIER, E. y C. ROZENBERG, 1988. Del santuario al caserío. Acerca de la neolitización en la cordillera de los Andes Centrales. Bulletin de l'Institut Français d'Etudes Andines XVII (2): 23-40.

BROWN, J., 1995. On mortuary analysis with special reference to the saxe Bindford Research Program. En Regional approaches to mortuary analysis, L. Anderson (Ed.), pp. 3-26. Plenum Press, Nueva York y Londres.

BUENO, L., 2004 Ms. Flotación en Tulan-85. Informe de práctica profesional, Departamento de Antropología, Facultad de Ciencias Sociales, Universidad de Chile, Santiago.

BURGER, R. y L. SALAZAR-BURGER, 1985. The early ceremonial center of Huaricoto. En Early ceremonial architecture, C. B. Donnan (Ed.), pp. 111-138. Dumbarton Oaks, Washington D. C.

CARTAJENA, I., 1994. Determinación de restos óseos de camélidos en dos yacimientos del Loa Medio (II Región). Estudios Atacameños 11: 25-52. 
CARTAJENA, I., L. NUÑEZ y M. GROSJEAN, 2003 Ms. Los camélidos en la vertiente occidental de la Puna de Atacama: Una visión desde el Arcaico Temprano. Ponencia presentada al III Taller Internacional de Zooarqueología de Camélidos Sudamericanos. Instituto Interdisciplinario de Tilcara, Tilcara.

2005 Ms. Animal utilization and camelid domestication in the Atacama Desert 13000-3500 cal. BP. Ponencia presentada al $2^{\text {nd }}$ Southern deserts conference: Human-environment interaction in southern hemisphere deserts. Past, present and future. Arica.

CORNEJO, L., 1991. La molienda en el Pukara de Turi. Chungara 24/25: 125-144.

COSTA, A., 2005 Ms. Informe de determinación de individuos infantiles del sitio Tulan-54. Informe de Avance Proyecto FONDECYT 1020316.

DE SOUZA, P., 2006. Los sistemas de proyectiles durante el proceso arcaico-formativo de la Puna de Atacama: Una aproximación desde el análisis de las puntas de proyectil de quebrada Tulan. Tesis para optar al grado de Magíster en Antropología. Universidad Católica del Norte-Universidad de Tarapacá, San Pedro de Atacama.

DOUGHERTY, B., 1972. Las pipas de fumar arqueológicas de la provincia de Jujuy. Relaciones de la Sociedad Argentina de Antropología II: 83-90.

DRANSART, P., 1991. Fibre to fabric: The role of fibre in camelid economics in prehispanic and contemporary Chile. $\mathrm{Ph}$. D. Thesis, Faculty Board of Anthropology and Geography, Oxford University, Oxford.

ELIADE, M., 1959. The sacred and the profane. Harcourt, Brace and World Inc. W. R. Trask, Nueva York.

ESCOLA, P., L. NUÑEZ y S. HOCSMAN, 2005 Ms. Distribution and circulation of obsidian in Puna de Atacama (ca. 4500$3000 \mathrm{AP})$.

FERNANDEZ, J., 1988-9. Ocupaciones alfareras (2860+160 AP) en la cueva de Cristóbal, Puna de Jujuy, Argentina. Relaciones de la Sociedad Argentina de Antropología XVII (2): 139-172.

GALLARDO, F., 2001. Arte rupestre y emplazamiento durante el Formativo Temprano en la cuenca del río Salado (Desierto de Atacama, norte de Chile). Boletín del Museo Chileno de Arte Precolombino 8: 83-97.

GALLARDO, F. y H. YACOBACCIO, 2005. Wild or domesticated? Camelids in early formative rock art of the Atacama Desert (Northern Chile). Latin American Antiquity 16 (2): $115-130$

GALLARDO F., C. SINCLAIRE y C. SILVA, 1999. Arte rupestre, emplazamiento y paisaje en la cordillera del Desierto de Atacama. En Arte Rupestre en los Andes de Capricornio, J. Berenguer y F. Gallardo (Eds.), pp. 58-96. Museo Chileno de Arte Precolombino, Santiago.
GARCIA, L., 1998. Arqueología de asentamientos formativos en la Puna Oriental y su borde, provincia de Jujuy. El cambio hacia una vida crecientemente sedentaria y productiva en Azul Pampa, Departamento de Humahuaca. Tesis de Doctorado, Facultad de Filosofía y Letras, Universidad de Buenos Aires, Buenos Aires.

GOÑI, R. A. y D. OLIVERA, 1996. La caza como variable independiente: Análisis comparativo de registros arqueológicos de la Puna y Patagonia argentinos. En Proceedings of the XIII Congress International Union of Prehistoric and Protohistoric Sciences, vol. 6, pp. 1369-1378, A.B.A.C.O. Edizione, Forli.

GROSJEAN, M., B. VALERO GARCES, A. SCHWALB, M. GEYH, B. MESSERLY y K. KELTS, 1996. Limnogeology of Laguna Miscanti: Evidence for Mid to Late Holocene moisture changes in the Atacama Altiplano (Northern Chile). Journal of Paleolimnology 16: 1-21.

GROSJEAN, M., L. NUÑEZ e I. CARTAJENA, 2005. Cultural response to climate change in the Atacama Desert. En $23^{\circ}$ South: Archaeology and environmental history of the southern desert, M. Smith y P. Hesse (Eds.), pp 156-171. National Museum of Australia, Canberra.

GUTIERREZ, F., 2006 Ms. La arquitectura en quebrada de Tulan: Construcción de espacios para vivir. Informe de Avance Proyecto FONDECYT 1020316.

HEDGES, R. E. M., R. A. HOUSLEY, I. A. LAW y C. R. BRONK, 1989. Radiocarbon dates from the Oxford AMS System: Archaeometry datelist 9. Archaeometry 31 (2): 225-234.

HOLDEN, T., 1991. Evidence of prehistoric diet from Northern Chile: Coprolites, gut contents and flotation samples from Tulan Quebrada. World Archaeology 22 (3): 321-331.

INGOLD, T., 1980. Hunters, pastoralists, and ranchers. Cambridge University Press, Cambridge.

JANUSEK, J., 2004. Household and city in Tiwanaku. En Andean archaeology, H. Silverman (Ed), pp. 183-208. Blackwell Publishing, Oxford.

KALAZICH, F., 2006 Ms. Tipología y contextos de uso de la alfarería temprana de Tulan, Puna de Atacama. Informe de práctica profesional. Departamento de Antropología, Facultad de Ciencias Sociales, Universidad de Chile, Santiago.

LABARCA, R., 2005. Zooarqueología de fauna menor en la Puna Salada: El caso de quebrada Tulan (II Región, Chile). Tesis para optar al Título de Arqueólogo. Departamento de Antropología, Facultad de Ciencias Sociales, Universidad de Chile, Santiago.

LATORRE, C., J. BETANCOURT, K. RYLANDER y J. QUADE, 2002. Vegetation invasions into absolute desert: A 45 k.y. rodent middenrecord form the Calama-Salar de Atacama basins, Northern Chile (Lat. 22-24 ${ }^{\circ}$ S). Geological Society of America Bulletin 114 (2): 349-366. 
LAVALLEE, D., 1989. Quelques aspects de la neolithisation andine. En Neolithisations. Proche et Moyen Orient, Mediterranee orientale, Nord de l'Afrique, Europe meridionale, Chine, Amerique du Sud, O. Aurenche y J. Cauvin (Eds.), pp. 319-332. BAR International Series 516 CNRS, Universite Lumiére-Lyon, Lyon.

2000. The first south americans. The peopling of a continent from the earliest evidence to high culture. University of Utah Press, Salt Lake City.

LAYTON, R., R. FOLEY y E. WILLIAMS, 1991. The transition between hunter and gathering and the specialized of resources: An socioecological approach. Current Antrhropology 32 (3): 255-274.

LEONARDIS, L. y G. F. LAU, 2004. Life, death, and ancestros. En Andean archaeology. H. Silverman (Ed.), pp. 77-115. Blackwell Publishing, Oxford.

MCANDREWS, T. L., 2005. Los sistemas de asentamientos Wankarani desde una perspectiva evolutiva. Estudios de una sociedad temprana basada en la aldea y su evolución cultural en el sur del altiplano central andino. Memoirs in Latin American Archaeology 15, University of Pitsburgh, Pitsburgh.

MCROSTIE, V., 2006 Ms. La transición arcaico-formativa en la quebrada de Tulan, sur del Salar de Atacama, Chile. Evidencias arqueobotánicas. Informe de Memoria de Título, Proyecto FONDECYT 1020316.

MEDINA, E., 2006 Ms. Análisis de una placa mineral proveniente del sitio formativo Tulan-54. Informe Final Proyecto FONDECYT 1020316.

MEIGHAN, C. W., 1980. Archaeology of Guatacondo. En Prehistoric trails of Atacama: Archaeology of Northern Chile, C. W. Meighan y A. L. True (Eds.), Monumenta Archaeologica 7, pp. 99-126. The Institute of Archaeology, The University of California, Los Angeles.

NIELSEN, A., 2006. Estudios internodales e interacción interregional en los Andes circumpuneños: Teoría, método y ejemplos de aplicación. En Esferas de interacción prehistóricas y fronteras nacionales modernas en los Andes Sur Centrales, H. Lechtman (Ed), pp. 29-69. Instituto de Estudios Peruanos e Institute of Andean Research, Lima.

NUÑEZ, L., 1981. Asentamiento de cazadores recolectores tardíos en la Puna de Atacama: Hacia el sedentarismo. Chungara 8: 137-168.

— 1992. Ocupación arcaica en la Puna de Atacama: Secuencia, movilidad y cambio. En Prehistoria sudamericana. Nuevas perspectivas, B. Meggers (Ed.), pp 283-307. Taraxacum, Washington D. C.

1994. Emergencia de complejidad y arquitectura jerarquizada en la Puna de Atacama: Evidencias del sitio Tulan-54. En Taller de Costa a Selva, M. E. Albeck (Ed.), pp. 85-115. Instituto Interdisciplinario de Tilcara, San Salvador de Jujuy.
— 1995. Evolución de la ocupación y organización del espacio atacameño. En Agua, ocupación del espacio y economía campesina en la región atacameña, P. Pourrut y L. Núñez (Eds.), pp. 18-60. Universidad Católica del Norte y ORSTOM, Antofagasta.

1999. Fase Tilocalar: Nuevas evidencias formativas en la Puna de Atacama (norte de Chile). En Formativo sudamericano. Una revaluación, P. Lederberger-Crespo (Ed.), pp. 227-242. ABYA-YALA, Cuenca.

2005. La naturaleza de la expansión aldeana durante el Formativo Tardío en la cuenca de Atacama. Chungara 37 (2): $165-193$

NUÑEZ, L. y J. HALL, 1982. Análisis de dieta y movilidad en un campamento arcaico en el norte de Chile. Bulletin de l'Institut Français d'Etudes Andines 11 (3-4): 90-113.

NUÑEZ, L., I. CARTAJENA y M. GROSJEAN, 1999. Un ecorrefugio oportunístico en la Puna de Atacama durante eventos áridos del Holoceno Medio. Estudios Atacameños 17: $125-174$.

NUÑEZ, L., M. GROSJEAN e I. CARTAJENA, 2002. Human occupations and climate change in the Puna de Atacama, Chile. Science 298 (5594): 821-824.

NUÑEZ, L., I. CARTAJENA, C. CARRASCO, P. DE SOUZA, 2005. El templete Tulan y sus relaciones formativas panandinas (norte de Chile). Bulletin de l'Institut Français d'Etudes Andines 34 (3): 299-320.

NUÑEZ, L., I. CARTAJENA, C. CARRASCO, P. DE SOUZA y M. GROSJEAN, 2006a. Patrones, cronología y distribución del arte rupestre arcaico tardío y formativo temprano en la cuenca de Atacama. En Tramas en la piedra, D. Fiore y M. Podestá (Eds.). Buenos Aires. En prensa.

NUÑEZ, L., I. CARTAJENA, C. CARRASCO y P. DE SOUZA, 2006b. El templete Tulan de la Puna de Atacama: Emergencia de complejidad ritual durante el Formativo Temprano (norte de Chile). Latin American Antiquity 17 (4). En prensa.

NUÑEZ, L., I. CARTAJENA, C. CARRASCO, P. DE SOUZA, 2006 Ms-a. Informe Final Proyecto FONDECYT 1020316.

NUÑEZ, L., P. DE SOUZA, I. CARTAJENA y C. CARRASCO, 2006 Ms-b. Quebrada Tulan: Evidencias de interacción circumpuneña durante el Formativo Temprano en el sureste de la cuenca de Atacama. Ponencia presentada al Taller Procesos sociales prehispánicos en los Andes Meridionales, Tilcara.

OLIVERA, D. 1998. Cazadores y pastores tempranos de la puna argentina. En Past and present in Andean Prehistory and Early History, S. Ahlgren, A. Muñoz, S. Jodin y P. Stenborg (Eds), pp. 153-180. Etnografiska Museet, Goteborg.

2000. El hombre y el ambiente en la puna argentina: El aporte de la arqueología al desarrollo de las economías regionales. Revista del Instituto Interdisciplinario de Tilcara 2: 5-30. 
PETERS, J., D. HELMER, D., A. VON DEN DRIESCH y M. SAÑA, 1999. Early animal husbandry in the Northern Levant. Paléorient 25 (2): 25-48.

POPPER, V., 1987. Prehistoric cultivation in the Puna de Atacama, Chile. Thesis Bachelor of Art. Departament of Anthropology, Harvard University, Cambridge.

PRICE T. D. y J. A. BROWN 1985. Aspect of hunter-gatherer complexity. En Prehistoric hunter-gatherer: The emergence of complexity, T. D. Price y J. A. Brown (Eds.), pp. 3-20. Academic Press, Nueva York.

RAFFINO, R., 1977. Las aldeas del Formativo Inferior de la quebrada del Toro (Salta, Argentina). Estudios Atacameños 5: 64-108.

REES, C., 1999. Elaboración distribución y consumo de cuentas de malaquita durante el Período Formativo en la vega de Turi y sus inmediaciones, Subregión del río Salado, norte de Chile. En Los tres reinos: Prácticas de recolección en el cono sur de América, C. Aschero, A. Korstanje y P. M. Vuoto (Eds.), pp. 83-94. Instituto de Arqueología y Museo, Universidad Nacional de Tucumán, Tucumán.

REES, C. y P. DE SOUZA, 2004. Producción lítica durante el Período Formativo en la Subregión del río Salado (norte de Chile). Chungara vol. especial: 453-465.

RICK, J., 1983 Prehistoric hunters of the High Andes. Academic Press, Nueva York.

RODRIGUEZ, F., 2005 Ms. Identificación de restos vegetales del sitio Tulan-52. Informe de Avance Proyecto FONDECYT 1020316.

RÖSSING, I., 1994. La deuda de ofrenda: Un concepto central de la religión andina. Revista Andina 12: 191-215.

SINCLAIRE, C., M. URIBE, P. AYALA y J. GONZALEZ, 1998. La alfarería del Período Formativo en la región del Loa Superior: Sistematización y tipología. Contribución Arqueológica 5, T II, pp. 285-314. Copiapó.

SINCLAIRE, C., 2004. Prehistoria del Período Formativo en la cuenca del río Salado (Región del Loa Superior): Un estado de la cuestión. Chungara vol. especial: 619-639.

SOTO, C., 2006 Ms. Cuentas de collar en la quebrada de Tulan, características y diferencias entre los periodos Arcaico y Formativo. Informe de práctica profesional, Departamento de Antropología, Facultad de Ciencias Sociales, Universidad de Chile, Santiago.

STEIN, G., 2002. From passive periphery to active agents: Emerging perspectives in the archaeology of interregional interaction. American Anthropologist 104 (3): 903-916.
TARRAGO, M., 1989. Contribución al conocimiento arqueológico de las poblaciones de los oasis de San Pedro de Atacama en relación con los otros pueblos puneños, en especial, el sector septentrional del valle Calchaquí. Tesis para optar al Título de Doctor en Historia, especialidad Antropología. Universidad Nacional de Rosario, Facultad de Humanidades y Artes, Argentina.

THOMAS, C., A. BENAVENTE, I. CARTAJENA y L. CONTRERAS, 2002. Una secuencia de fechados por termoluminiscencia para la localidad de Chiu Chiu: Sitios Chiu Chiu-273 y 275. Boletín de la Sociedad Chilena de Arqueología 33/34: 84-89.

VENTURA, B., 1999. Arqueología de los valles orientales y las serranías de Zenta y Santa Victoria, Salta. Tesis de Doctorado, Facultad de Filosofía y Letras, Universidad de Buenos Aires, Buenos Aires.

URIBE, M., 2003 Ms. La cerámica arqueológica del sitio Tulan-54: Análisis tipológico y depositacional de un sitio formativo temprano del Salar de Atacama. Informe de Avance Proyecto FONDECYT 1020316.

2006. Sobre cerámica, su origen y complejidad social en los Andes del Desierto de Atacama, norte de Chile. En Esferas de interacción prehispánicas y fronteras nacionales modernas. Los Andes Sur Centrales, H. Lechtman (Ed.), pp. 449-502. Instituto de Estudios Peruanos e Institute of Andean Research, Lima.

WHEELER, J., E. PIRES-FERREIRA y P. KAULICKE, 1977. Domesticación en los Andes durante el Precerámico: Un modelo. Journal de la Société des Américanistes XIV: 155-165.

WING, E., 1972. Utilization of animal resources in the Peruvian Andes. Apendix IV. En Andes 4, Excavations at Kotosh, Perú 1963 and 1969, S. Izumi y K. Terada (Eds.), pp. 352372. University of Tokyo Press, Tokyo.

YACOBACCIO, H., 2001. Cazadores complejos y domesticación de camélidos. En El uso de los camélidos a través del tiempo, G. L. Mengoni, D. Olivera y H. Yacobaccio (Eds.), pp. 261-282. GZC/ICAZ, Buenos Aires.

YACOBACCIO, H. y C. MADERO, 1988 Ms. ¿Qué hacían los pastores con sus huesos? Precirculado presentado al IX Congreso Nacional de Arqueología Argentina, Buenos Aires.

YACOBACCIO, H., D. ELKIN y D. OLIVERA, 1994. ¿El fin de las sociedades cazadoras? El proceso de domesticación animal en los Andes Centro Sur. En Arqueología de cazadores recolectores: Límites, casos y aperturas, J. L. Lanata y L. Borrero (Eds.), Arqueología Contemporánea 5: $23-32$ 